\title{
Optimal Method for Catastrophic Faults Diagnosis in RC Ladder Network
}

\author{
Abhilasha Rani Goel and Mohd Wajid \\ Electronics and Communication Engineering, Jaypee University of Information Technology, Waknaghat, \\ P.O. Waknaghat, Teh Kandaghat, District Solan, Himachal Pradesh 173234, India \\ Correspondence should be addressed to Mohd Wajid; wajidiitd@ieee.org \\ Received 16 March 2016; Revised 22 May 2016; Accepted 29 May 2016 \\ Academic Editor: Antonio J. Marques Cardoso
}

Copyright (C) 2016 A. R. Goel and M. Wajid. This is an open access article distributed under the Creative Commons Attribution License, which permits unrestricted use, distribution, and reproduction in any medium, provided the original work is properly cited.

The RC ladder network has been analyzed for various catastrophic fault detection using minimal number of measurements. Generally, electronic circuit testing procedure is very exhaustive and includes higher cost; the presented approach will save fault diagnosis time. It is not possible to analyze the big RC ladder network to give the good fault coverage, so the ladder network has been broken into segments of different sizes. However, if segment size is small, it will cause more area overhead compared to bigger step size in terms of the interconnections and pins on the integrated circuit. A systematic and detailed analysis for one-step, twostep, three-step, and four-step RC ladder networks has been carried out for various faults and optimal step size is proposed. It has been investigated that three measurements are optimal to localize different catastrophic faults in a RC ladder network.

\section{Introduction}

The resistive ladder network has been analyzed for detecting various catastrophic faults associated with it, where only resistive components are considered [1]. However, there are many circuits which use capacitor also, like RC ladder network. The ladder networks with resistor and capacitors are widely used in filters, phase shifter circuits, oscillators, and so forth $[2,3]$. As per the knowledge of authors, the related literature on the fault diagnosis in RC network is limited. In this and next paragraph, we have presented available existing methods/algorithms associated with fault identification in the circuits. Huang et al. have presented an approach based on an assemblage of learning machine that is trained to guide through diagnosis decision. It diagnoses the hard/soft fault by using defect filter. The hard faults have been diagnosed using the multiclass classifier and the soft fault is diagnosed using the inverse regression functions. The disadvantage of this method is in resolving the ambiguity; this method uses some auxiliary circuit specific fault diagnosis rules [4]. Kyzioł et al. [5] have given an algorithm to diagnose the catastrophic faults in analog circuits. This algorithm uses the Particle
Swarm Optimization (PSO); it uses more than one dimension like load resistance and reactance, generator resistance, and reactance and generator frequency to diagnose the faults. They have shown that increasing the numbers of dimensions of search space influences the identification of states of circuit under test (CUT). The disadvantage of this method is that it can diagnose only single catastrophic fault of CUT.

Starzyk et al. [6] have proposed an algorithm based on entropy index of available test points, where two-dimensional integer coded dictionary is created whose entries are measurements associated with faults and test points. Though this algorithm can be used for medium and large networks also, it is very costly. Huang et al. [7] have given a method to diagnose the local spot defects in analog circuit. This method is based on the combination of multiclass classifiers that are trained using data from fault simulation. The problem has been viewed as pattern recognition task. The method starts by inductive fault analysis (IFA) which results in a list of probable defects; then the defects are ranked based on their probability of occurrence. After that, multiclass classifiers are used to detect the fault. It is a probability based method, not so much accurate. 


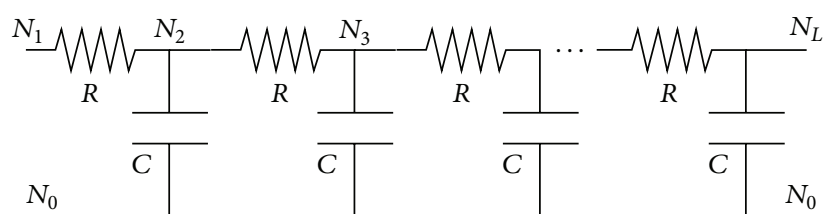

FIGURE 1: RC ladder network: $N_{i}$ indicates node number.

In the present work, we have analyzed the RC ladder network (Figure 1) for fault diagnosis. Two catastrophic faults, open and short, are considered in resistors and one catastrophic fault is considered in capacitors; that is, capacitor impedance is equal to zero. In integrated circuit, the separation between two wires cannot be very large, so infinite impedance of capacitor is not considered. Different size segments of RC ladder networks, that is, 1-step, 2-step, 3step, and 4-step, are assessed. In this paper, the impedance $X_{c}$ is varied as a function of $n$ as given in (1), where $1 \leq$ $n \leq 30$ and other parameters $R, \omega$, and $C$ are kept constant $\left(R=10 \mathrm{~K} \Omega, C=100 \mathrm{pF}\right.$, and $\left.\omega=2 \pi 10^{4} \mathrm{rad} / \mathrm{sec}\right)$ :

$$
X_{c}=\frac{1}{j n \omega c} .
$$

We have assumed that the network has only one fault at a time. $Z_{i j}$ is an equivalent impedance measured between $i$ th and $j$ th nodes (Figure 1). Notations gives the list of notations used.

To calculate the fault coverage, two characteristics are considered, that is, distinguishability and ambiguity. Distinguishability means that the impedance plot for any faulty case can be distinguished from the impedance plot of the faultless case, but it will not cover the overlapping of plots of any two distinct faults. Because distinguishability does not cover the overlapping of two plots for any two faulty cases, ambiguity is defined separately. Ambiguity means that the plots for any of the two faulty cases overlap each other and it does not cover the faultless case. A deviation $d$ (see (2)) of $2 \%$ is considered as acceptable value in the given impedance plots as taken in [1]. If the plot for one fault lies within $2 \%$ of another plot for the given value of $n$, then both of those plots are considered as nondistinguishable or ambiguous:

$$
\begin{aligned}
d= & \frac{\mid Z_{i j} \text { for faultless case }|-| Z_{i j} \text { for faulty case } \mid}{\mid Z_{i j} \text { for faultless case } \mid} \\
& \times 100 .
\end{aligned}
$$

\section{Analysis}

In this section, a large RC ladder network is broken into small size RC ladder networks, namely, one-step, two-step, three-step, and four-step RC network. These different step size networks are analyzed for fault detection for different values of $n, 1 \leq n \leq 30$. In this paper, all graphs are shown only for $n=5$ to 30 , because for $n=1$ to 4 some of the plots have very high values as compared to others, so that they cannot be plotted. Also, it has been assumed that $a=\omega n R C$.
TABLE 1: Expressions for single-step RC ladder network.

\begin{tabular}{lc}
\hline Fault type & $\left|Z_{01}\right|^{2}$ \\
\hline$R_{12}$ short & $\frac{1}{\omega^{2} n^{2} C^{2}}$ \\
$R_{12}$ open & Infinity \\
$X_{C_{20}}$ short & $R^{2}$ \\
\hline
\end{tabular}

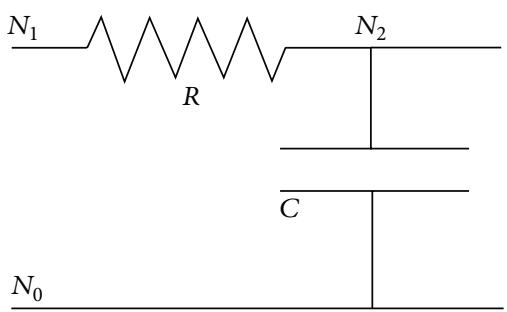

FIGURE 2: Single-step RC ladder network.

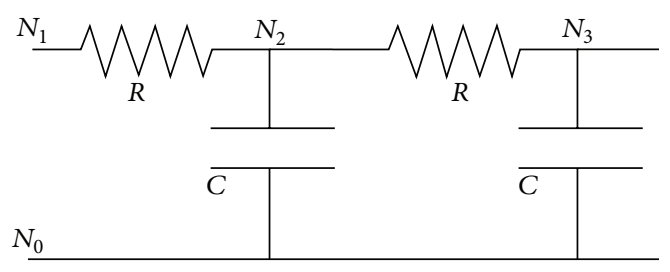

Figure 3: Two-step RC ladder network.

All the analysis is done mathematically and all the graphs are plotted in the MATLAB software.

2.1. Single-Step RC Ladder Network. The single-step RC ladder network is shown in Figure 2. In this network, only three faults exist, that is, $R_{12}$ short circuit, $R_{12}$ open circuit, and $C_{20}$ which is short; that is, $X_{C_{20}}=0$ :

$$
\left|Z_{01}\right|^{2}=\frac{1+(\omega n R C)^{2}}{\omega^{2} n^{2} C^{2}} .
$$

It can be concluded from Table 1 that all the three values of $\left|Z_{01}\right|^{2}$ for different fault types are distinct and faults can be detected with no ambiguity, so the fault coverage is $100 \%$. But computational complexity and area overhead are very large, because number of measurements will be equal to number of components and many numbers of single-step RC ladder network have to be tested to identify the faults of a big network [8]. Also, large numbers of observable nodes are required, so this cannot be considered from integrated circuit point of view. When we are breaking the big RC network into small RC network, this will also use additional circuits for the switches which lead to increase in area overhead $[1,9]$.

2.2. Two-Step RC Ladder Network. In this section, the detailed analysis of two-step RC ladder network as shown in Figure 3 is conducted. 
TABLE 2: Expressions for two-step RC ladder network.

\begin{tabular}{|c|c|c|c|}
\hline Fault type & $\left|Z_{01}\right|^{2}$ & $\left|Z_{02}\right|^{2}$ & $\left|Z_{13}\right|^{2}$ \\
\hline \multirow{2}{*}{ Faultless } & $a^{6}+11 a^{4}+21 a^{2}+4$ & $a^{4}+5 a^{2}+4$ & $a^{6}+20 a^{4}+64 a^{2}$ \\
\hline & $\begin{array}{c}\overline{\omega^{2} n^{2} C^{2}\left[a^{4}+8 a^{2}+16\right]} \\
a^{4}+5 a^{2}+4\end{array}$ & $\begin{array}{c}\overline{\omega^{2} n^{2} C^{2}\left[a^{4}+8 a^{2}+16\right]} \\
a^{4}+5 a^{2}+4\end{array}$ & $\begin{array}{c}\overline{\omega^{2} n^{2} C^{2}\left[a^{4}+8 a^{2}+16\right]} \\
4 a^{4}+16 a^{2}\end{array}$ \\
\hline$R_{12}$ short & $\overline{\omega^{2} n^{2} C^{2}\left[a^{4}+8 a^{2}+16\right]}$ & $\overline{\omega^{2} n^{2} C^{2}\left[a^{4}+8 a^{2}+16\right]}$ & $\overline{\omega^{2} n^{2} C^{2}\left[a^{4}+8 a^{2}+16\right]}$ \\
\hline$R_{12}$ open & Infinity & $\frac{a+5 a^{2}+4}{\omega^{2} n^{2} C^{2}\left[a^{4}+8 a^{2}+16\right]}$ & Infinity \\
\hline$X_{C_{20}}$ short & $R^{2}$ & $\frac{a^{4}+a^{2}}{\omega^{2} n^{2} C^{2}\left[a^{4}+2 a^{2}+1\right]}$ & $\frac{a^{6}+5 a^{4}+4 a^{2}}{\omega^{2} n^{2} C^{2}\left[a^{4}+2 a^{2}+1\right]}$ \\
\hline$R_{23}$ short & $\begin{array}{c}\frac{4 a^{2}+1}{4 \omega^{2} n^{2} C^{2}} \\
a^{2}+1\end{array}$ & $\frac{1}{4 \omega^{2} n^{2} C^{2}} \frac{1}{1}$ & $\begin{array}{c}R^{2} \\
a^{2}+4\end{array}$ \\
\hline$R_{23}$ open & $\begin{array}{c}\overline{\omega^{2} n^{2} C^{2}} \\
a^{6}+5 a^{4}+4 a^{2}\end{array}$ & $\overline{\omega^{2} n^{2} C^{2}}$ & $\begin{array}{c}\overline{\omega^{2} n^{2} C^{2}} \\
a^{6}+5 a^{4}+4 a^{2}\end{array}$ \\
\hline$X_{C_{30}}$ short & $\overline{\omega^{2} n^{2} C^{2}\left[a^{4}+2 a^{2}+1\right]}$ & 0 & $\overline{\omega^{2} n^{2} C^{2}\left[a^{4}+2 a^{2}+1\right]}$ \\
\hline
\end{tabular}

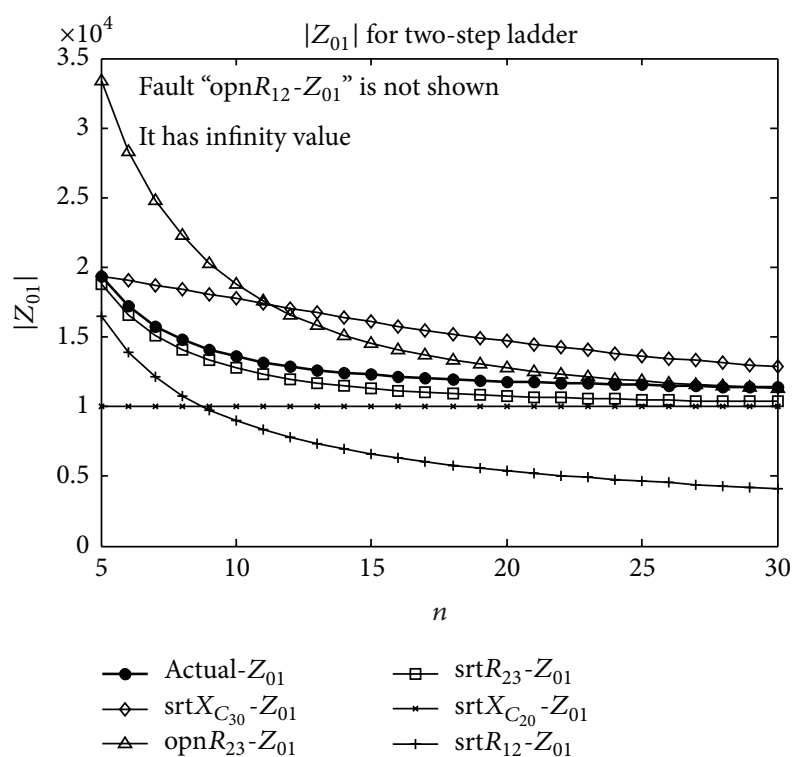

Figure 4: Plot of $\left|Z_{01}\right|$ versus " $n$ " for different faults of two-step network.

TABLE 3: Distinguishability for two-step RC ladder network.

\begin{tabular}{llc}
\hline Fault type & Distinguishability & By measuring \\
\hline$R_{12}$ short & Distinguishable at all $n$ & $Z_{13}$ \\
$R_{12}$ open & Distinguishable at all $n$ & $Z_{01}$ or $Z_{13}$ \\
$X_{C_{20}}$ short & Distinguishable at all $n$ & $Z_{01}$ \\
$R_{23}$ short & Distinguishable at all $n$ & $Z_{13}$ \\
$R_{23}$ open & Distinguishable at all $n$ & $Z_{02}$ \\
$X_{C_{30}}$ short & Distinguishable at all $n$ & $Z_{02}$ \\
\hline
\end{tabular}

Table 2 gives the $\left|Z_{01}\right|^{2},\left|Z_{02}\right|^{2}$, and $\left|Z_{13}\right|^{2}$ expressions for considering each and every fault as well as for faultless case.

Figures 4,5 , and 6 show the values of magnitude of $Z_{01}$, $Z_{02}$, and $Z_{13}$, respectively, plotted against " $n$."

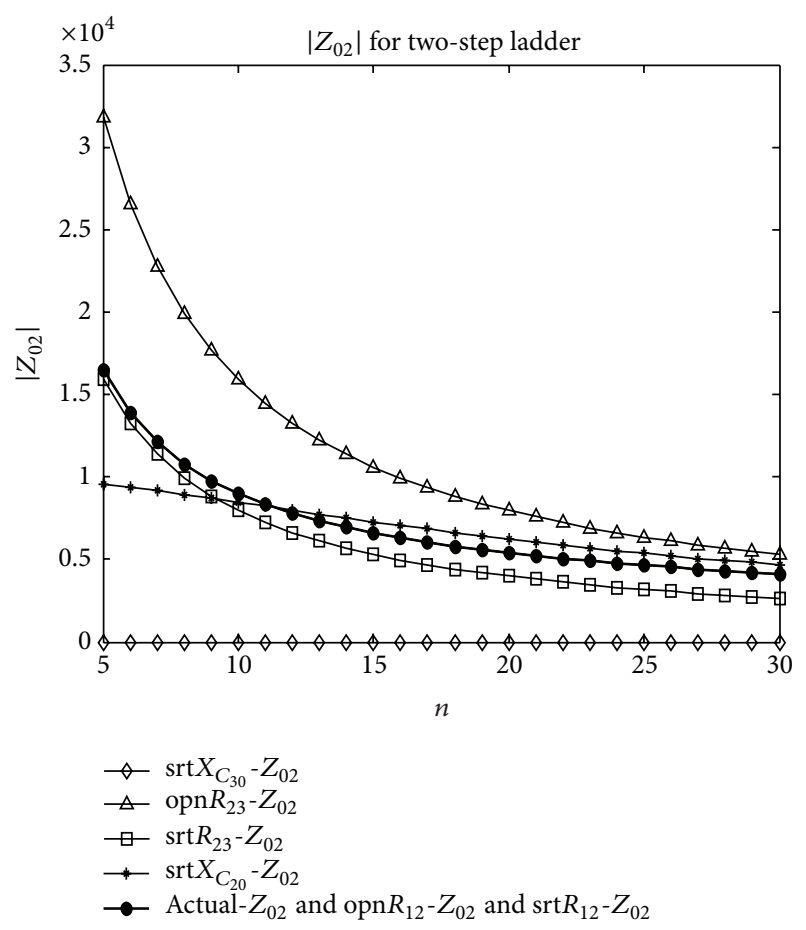

Figure 5: Plot of $\left|Z_{02}\right|$ versus " $n$ " for different faults of two-step network.

Table 3 shows the conclusion derived from Figures 4, 5, and 6 about faults distinguishability and required measuring parameters for the same.

Tables 4, 5, and 6 show the ambiguity for each fault which is not distinguishable from the measurement of $\left|Z_{01}\right|,\left|Z_{02}\right|$, and $\left|Z_{13}\right|$, respectively.

Table 7 gives the conclusion derived from Tables 4, 5, and 6.

Figure 7 shows the fault coverage for two-step RC ladder network. Fault coverage is $100 \%$ except for $n=1$. All three measurements, that is, $Z_{01}, Z_{02}$, and $Z_{13}$, are required to calculate the distinguishability and ambiguity. 
TABLE 4: Ambiguity from $\left|Z_{01}\right|$ for two-step RC ladder network.

\begin{tabular}{ll}
\hline Fault & Ambiguity with the following \\
\hline$R_{12}$ short & $X_{C_{20}} \operatorname{short~}(n=8,9), R_{23}$ short $(n=1), X_{C_{30}}$ short $(n=4)$ \\
$R_{12}$ open & No ambiguity \\
$X_{C_{20}}$ short & $R_{12} \operatorname{short~}(n=8,9), R_{23} \operatorname{short~}(n \geq 18)$ \\
$R_{23}$ short & $R_{12} \operatorname{short~}(n=1), X_{C_{20}} \operatorname{short}(n \geq 18), X_{C_{30}} \operatorname{short}(n=5)$ \\
$R_{23}$ open & $X_{C_{30}} \operatorname{short~}(n=11,12,13)$ \\
$X_{C_{30}}$ short & $R_{12} \operatorname{short~}(n=4), R_{23}$ open $(n=11,12,13), R_{23}$ short $(n=5)$ \\
\hline
\end{tabular}

TABLe 5: Ambiguity from $\left|Z_{02}\right|$ for two-step RC ladder network.

\begin{tabular}{ll}
\hline Fault & Ambiguity with the following \\
\hline$R_{12}$ short & $R_{12}$ open $(\operatorname{all} n), X_{C_{20}}$ short $(n \geq 10), R_{23}$ short $(n \leq 10)$ \\
$R_{12}$ open & $R_{12}$ short $($ all $n), X_{C_{20}}$ short $(n \geq 10), R_{23}$ short $(n \leq 10)$ \\
$X_{C_{20}}$ short & $R_{12}$ short $(n \geq 10), R_{12}$ open $(n \geq 10), R_{23}$ short $(n=9,10), R_{23}$ open $(n \geq 26)$ \\
$R_{23}$ short & $R_{12}$ short $(n \leq 10), R_{12}$ open $(n \leq 10), X_{C_{20}}$ short $(n=9,10)$ \\
$R_{23}$ open & $X_{C_{20}}$ short $(n \geq 26)$ \\
$X_{C_{30}}$ short & No ambiguity \\
\hline
\end{tabular}

TABLE 6: Ambiguity from $\left|Z_{13}\right|$ for two-step RC ladder network.

\begin{tabular}{ll}
\hline Fault & Ambiguity with the following \\
\hline$R_{12}$ short & $R_{23}$ short $(n \leq 15), R_{23}$ open $(n \geq 21)$ \\
$R_{12}$ open & No ambiguity \\
$X_{C_{20}}$ short & $X_{C_{30}}$ short $($ all $n)$ \\
$R_{23}$ short & $R_{12}$ short $(n \leq 15)$ \\
$R_{23}$ open & $R_{12}$ short $(n \geq 21)$ \\
$X_{C_{30}}$ short & $X_{C_{20}}$ short $($ all $n)$ \\
\hline
\end{tabular}

2.3. Three-Step RC Ladder Network. In this section, detailed analysis of three-step RC ladder network (Figure 8) is done.

For faultless network, the expression for $\left|Z_{01}\right|^{2}$ is given by

$$
\left|Z_{01}\right|^{2}=\frac{a^{10}+23 a^{8}+165 a^{6}+378 a^{4}+244 a^{2}+9}{\omega^{2} n^{2} C^{2}\left[a^{8}+20 a^{6}+118 a^{4}+180 a^{2}+81\right]} .
$$

Table 8 gives the $\left|Z_{01}\right|^{2}$ expression for considering each and every fault. Similar analysis is done for $\left|Z_{02}\right|^{2}$ and $\left|Z_{14}\right|^{2}$ and the results are shown below.

For a faultless network, the expression for $\left|Z_{02}\right|^{2}$ and $\left|Z_{14}\right|^{2}$ is given by

$$
\begin{aligned}
& \left|Z_{22}\right|^{2}=\frac{a^{8}+17 a^{6}+80 a^{4}+73 a^{2}+9}{\omega^{2} n^{2} C^{2}\left[a^{8}+20 a^{6}+118 a^{4}+180 a^{2}+81\right]}, \\
& \left|Z_{14}\right|^{2}=\frac{\left[a^{9}+20 a^{7}+79 a^{5}+2124 a^{3}\right]^{2}+\left[2 a^{8}+34 a^{6}+224 a^{4}+720 a^{2}\right]^{2}}{\omega^{2} n^{2} C^{2}\left[a^{8}+18 a^{6}+57 a^{4}+1336 a^{2}+144\right]} .
\end{aligned}
$$

Table 9 gives the $\left|Z_{02}\right|^{2}$ expressions for considering each and every fault and Table 10 gives the $\left|Z_{14}\right|^{2}$ expressions for each and every fault.

Figure 9 shows the values of magnitude of $Z_{01}$ plotted against " $n$." Fault opn $R_{12}-Z_{01}$ is not shown in Figure 9, as it has value of infinity. Therefore, eight curves are shown corresponding to other short and open faults.

Figure 10 shows the values of magnitude of $Z_{02}$ plotted against " $n$." Actual- $Z_{02}, \operatorname{srt} R_{12}-Z_{02}$, and opn $R_{12}-Z_{02}$ overlap each other, so all these plots are represented by bold line in Figure 10; fault opn $R_{34}-Z_{02}$ is excluded from the graph because it has very high value as compared to other faults. Therefore, 6 lines are shown corresponding to other short and open faults.
Figure 11 shows the values of magnitude of $Z_{14}$ versus " $n$." Faults $\operatorname{srt} X C_{20}-Z_{14}$ and $\operatorname{srt} X C_{40}-Z_{14}$ are overlapping; opn $R_{23}-Z_{14}$ and opn $R_{34}-Z_{14}$ are overlapping; srt $R_{23}-Z_{14}$ and $\operatorname{srt} R_{34}-Z_{14}$ are overlapping; one of the faults opn $R_{12}-Z_{14}$ is not shown in Figure 11, as it has value of infinity. Therefore only 5 curves are shown corresponding to other short and open faults.

Table 11 shows the conclusion derived from Figures 9-11.

Tables 12, 13, and 14 show the ambiguity for each fault which is not distinguishable from $\left|Z_{01}\right|,\left|Z_{02}\right|$, and $\left|Z_{14}\right|$, respectively. Table 15 gives the conclusion derived from Tables 12,13 , and 14. Figure 12 shows the fault coverage for three-step RC ladder network. Fault coverage is $100 \%$ for some values of " $n$." For $n=2$ to 10 and 13 to 20 the fault coverage is $100 \%$, but for other values of $n$ fault coverage is less than $100 \%$. All 


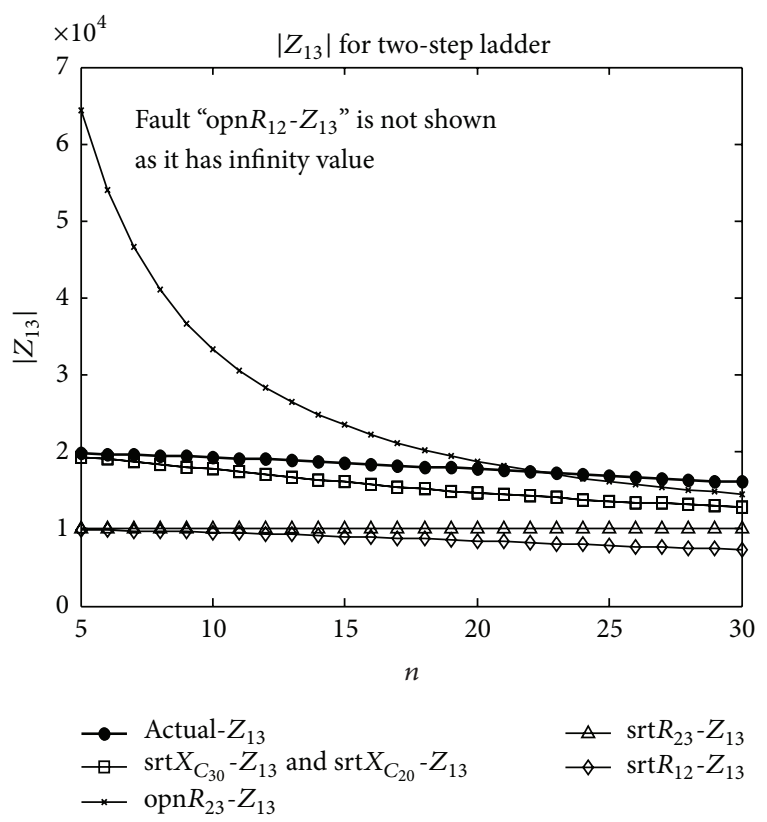

Figure 6: Plot of $\left|Z_{13}\right|$ versus " $n$ " for different faults of two-step network.

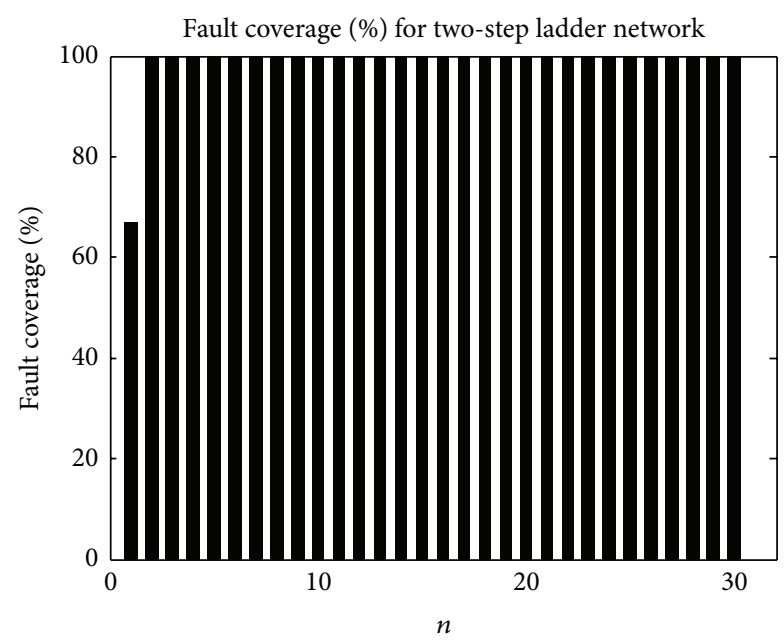

FiguRE 7: Fault coverage for two-step RC ladder network.
TABLE 7: Ambiguity from $\left|Z_{01}\right|,\left|Z_{02}\right|$, and $\left|Z_{13}\right|$ for two-step RC ladder network.

\begin{tabular}{lc}
\hline Fault & Ambiguity with the following \\
\hline$R_{12}$ short & $R_{23}$ short $(n=1)$ \\
$R_{12}$ open & No ambiguity \\
$X_{C_{20}}$ short & No ambiguity \\
$R_{23}$ short & $R_{12}$ short $(n=1)$ \\
$R_{23}$ open & No ambiguity \\
$X_{C_{30}}$ short & No ambiguity \\
\hline
\end{tabular}

the measurements, that is, $Z_{01}, Z_{02}$, and $Z_{14}$ are required to calculate the distinguishability and ambiguity.

2.4. Four-Step RC Ladder Network. In this section, detailed analysis of four-step RC ladder network (Figure 13) has been performed. As in the previous case, this network is also analyzed for $n=1$ to 30 .

For faultless network, the expression for $\left|Z_{01}\right|^{2}$ is

$$
\begin{aligned}
& \left|Z_{11}\right|^{2} \\
& =\frac{\left[a^{7}+17 a^{5}+63 a^{3}+30 a\right]^{2}+\left[a^{6}+14 a^{4}+34 a^{2}+4\right]^{2}}{\omega^{2} n^{2} C^{2}\left[a^{6}+16 a^{4}+52 a^{2}+16\right]^{2}} .
\end{aligned}
$$

Table 16 gives the expressions of $\left|Z_{01}\right|^{2}$ for all faults. In these expressions,

$$
a=\omega n R C,
$$

where $\omega=2 \pi f$ and $f=10 \mathrm{KHz}$. The parameter " $n$ " is varied from 1 to 30

Similar analysis is done for $\left|Z_{02}\right|^{2}$ and $\left|Z_{15}\right|^{2}$; for a faultless network the expression for $\left|Z_{02}\right|^{2}$ and $\left|Z_{15}\right|^{2}$ is given by

$$
\begin{aligned}
& \left|Z_{22}\right|^{2}=\frac{\left[a^{5}+11 a^{3}+14 a\right]^{2}+\left[a^{6}+14 a^{4}+34 a^{2}+4\right]^{2}}{\omega^{2} n^{2} C^{2}\left[a^{6}+16 a^{4}+52 a^{2}+16\right]^{2}}, \\
& \left|Z_{15}\right|^{2}=\frac{\left[a^{9}+22 a^{7}+144 a^{5}+352 a^{3}+256 a\right]^{2}+\left[2 a^{8}+36 a^{6}+192 a^{4}+320 a^{2}\right]^{2}}{\omega^{2} n^{2} C^{2}\left[a^{8}+20 a^{6}+116 a^{4}+224 a^{2}+64\right]^{2}} .
\end{aligned}
$$

Table 17 gives the $\left|Z_{02}\right|^{2}$ expressions for considering each and every fault and Table 18 gives the $\left|Z_{15}\right|^{2}$ expressions for each and every fault.

Figure 14 shows the values of magnitude of $Z_{01}$ on the $y$-axis, plotted against " $n$ " on the $x$-axis. Fault opn $R_{12}-Z_{01}$ is not shown in Figure 14, as it has value of infinity. Therefore, 11 lines are shown corresponding to other short and open faults.

Figure 15 shows the values of magnitude of $Z_{02}$ on the $Y$-axis, plotted against " $n$ " on the $X$-axis. Actual- $Z_{02}$, 
TABLE 8: $\left|Z_{01}\right|^{2}$ expression for three-step RC ladder network.

\begin{tabular}{lcc}
\hline Fault location & Short fault $\left|Z_{01}\right|^{2}$ & ${\text { Open fault }\left|Z_{01}\right|^{2}}^{2}$ \\
$R_{12}$ & $\frac{a^{8}+17 a^{6}+80 a^{4}+73 a^{2}+9}{\omega^{2} n^{2} C^{2}\left[a^{8}+20 a^{6}+118 a^{4}+180 a^{2}+81\right]}$ & Infinity \\
$X_{C_{20}}$ & $R^{2}$ & None \\
$R_{23}$ & $\frac{16 a^{6}+84 a^{4}+112 a^{2}+9}{\omega^{2} n^{2} C^{2}\left[8 a^{4}+72 a^{2}+81\right]}$ & $\frac{a^{2}+1}{\omega^{2} n^{2} C^{2}}$ \\
$X_{C_{30}}$ & $\frac{a^{6}+5 a^{4}+4 a^{2}}{\omega^{2} n^{2} C^{2}\left[a^{4}+2 a^{2}+1\right]}$ & None \\
$R_{34}$ & $\frac{16 a^{6}+120 a^{4}+193 a^{2}+9}{\omega^{2} n^{2} C^{2}\left[16 a^{4}+72 a^{2}+81\right]}$ & $\frac{a^{6}+11 a^{4}+21 a^{2}+4}{\omega^{2} n^{2} C^{2}\left[a^{4}+8 a^{2}+16\right]}$ \\
$X_{C_{40}}$ & $\frac{a^{10}+17 a^{8}+80 a^{6}+73 a^{4}+9 a^{2}}{\omega^{2} n^{2} C^{2}\left[a^{8}+14 a^{6}+51 a^{4}+14 a^{2}+1\right]}$ & None \\
\hline
\end{tabular}

TABLE 9: $\left|Z_{02}\right|^{2}$ expression for three-step RC ladder network.

\begin{tabular}{lcc}
\hline Fault location & Short fault $\left|Z_{02}\right|^{2}$ & Open fault $\left|Z_{02}\right|^{2}$ \\
\hline$R_{12}$ & $\frac{a^{8}+17 a^{6}+80 a^{4}+73 a^{2}+9}{\omega^{2} n^{2} C^{2}\left[a^{8}+20 a^{6}+118 a^{4}+180 a^{2}+81\right]}$ & $\frac{a^{8}+17 a^{6}+80 a^{4}+73 a^{2}+9}{\omega^{2} n^{2} C^{2}\left[a^{8}+20 a^{6}+118 a^{4}+180 a^{2}+81\right]}$ \\
$X_{C_{20}}$ & $\frac{a^{8}+11 a^{6}+29 a^{4}+4 a^{2}}{\omega^{2} n^{2} C^{2}\left[a^{8}+14 a^{6}+51 a^{4}+14 a^{2}+1\right]}$ & None \\
$R_{23}$ & $\frac{16 a^{4}+40 a^{2}+9}{\omega^{2} n^{2} C^{2}\left[16 a^{4}+72 a^{2}+81\right]}$ & $\frac{a^{4}+5 a^{2}+4}{\omega^{2} n^{2} C^{2}\left[a^{4}+8 a^{2}+16\right]}$ \\
$X_{C_{30}}$ & $\frac{a^{4}+a^{2}}{\omega^{2} n^{2} C^{2}\left[a^{4}+2 a^{2}+1\right]}$ & None \\
$R_{34}$ & $\frac{4 a^{4}+13 a^{2}+9}{\omega^{2} n^{2} C^{2}\left[16 a^{4}+72 a^{2}+81\right]}$ & 1 \\
$X_{C_{40}}$ & 0 & $\frac{\omega^{2} n^{2} C^{2}}{\text { None }}$ \\
\hline
\end{tabular}

TABLE 10: $\left|Z_{14}\right|^{2}$ expression for three-step RC ladder network.

\begin{tabular}{lcr}
\hline Fault location & Short fault $\left|Z_{14}\right|^{2}$ & Open fault $\left|Z_{14}\right|^{2}$ \\
\hline$R_{12}$ & $\frac{\left[2 a^{7}+34 a^{5}+512 a^{3}-288 a\right]^{2}+\left[2 a^{8}+34 a^{6}+128 a^{4}+1056 a^{2}\right]^{2}}{\omega^{2} n^{2} C^{2}\left[a^{8}+18 a^{6}+57 a^{4}+1336 a^{2}+144\right]^{2}}$ & Infinity \\
$X_{C_{20}}$ & $\frac{a^{10}+17 a^{8}+80 a^{6}+73 a^{4}+9 a^{2}}{\omega^{2} n^{2} C^{2}\left[a^{8}+14 a^{6}+51 a^{4}+14 a^{2}+1\right]}$ & None \\
$R_{23}$ & $\frac{\left[4 a^{7}+50 a^{5}+208 a^{3}+288 a\right]^{2}+\left[6 a^{6}+48 a^{4}+96 a^{2}\right]^{2}}{\omega^{2} n^{2} C^{2}\left[4 a^{6}+41 a^{4}+136 a^{2}+144\right]^{2}}$ & $\frac{a^{6}+14 a^{4}+49 a^{2}+36}{\omega^{2} n^{2} C^{2}\left[a^{4}+8 a^{2}+16\right]}$ \\
$X_{C_{30}}$ & $\frac{a^{6}+10 a^{4}+9 a^{2}}{\omega^{2} n^{2} C^{2}\left[a^{4}+2 a^{2}+1\right]}$ & None \\
$R_{34}$ & $\frac{16 a^{6}+180 a^{4}+324 a^{2}}{\omega^{2} n^{2} C^{2}\left[16 a^{4}+72 a^{2}+81\right]}$ & $\frac{a^{6}+14 a^{4}+49 a^{2}+36}{\omega^{2} n^{2} C^{2}\left[a^{4}+8 a^{2}+16\right]}$ \\
$X_{C_{40}}$ & $\frac{a^{10}+17 a^{8}+80 a^{6}+73 a^{4}+9 a^{2}}{\omega^{2} n^{2} C^{2}\left[a^{8}+14 a^{6}+51 a^{4}+14 a^{2}+1\right]}$ & None \\
\hline
\end{tabular}

srt $R_{12}-Z_{02}$, and opn $R_{12}-Z_{02}$ are overlapping, so all these plots are represented by bold line in Figure 15; fault opn $R_{45}-Z_{02}$ was excluded from the graph, since it has very high value compared to the curves. Therefore, 9 lines are shown corresponding to other short and open faults.

Figure 16 shows the values of magnitude of $Z_{15}$ versus " $n$." Faults $\operatorname{srt} X_{C_{20}}-Z_{15}$ and $\operatorname{srt} X_{C_{50}}-Z_{15}$ are overlapping; $\operatorname{srt} X_{C_{30}}-Z_{15}$ and $\operatorname{srt} X_{C_{40}}-Z_{15}$ are overlapping; srt $R_{23}-Z_{15}$ and $\operatorname{srt} R_{45}-Z_{15}$ are overlapping; opn $R_{23}-Z_{15}$ and opn $R_{45}-Z_{15}$ are overlapping; one of the faults opn $R_{12}-Z_{15}$ is not shown in Figure 16, as it has value of infinity. Therefore 7 lines are shown corresponding to other short and open faults.

Table 19 shows the conclusion derived from Figures 14, 15, and 16 . 
TABLE 11: Distinguishability for three-step RC ladder network.

\begin{tabular}{lcc}
\hline Fault type & Distinguishability & By measuring \\
\hline$R_{12}$ short & Distinguishable at all $n$ & $Z_{01}$ \\
$R_{12}$ open & Distinguishable at all $n$ & $Z_{01}$ or $Z_{14}$ \\
$X_{C_{20}}$ short & Distinguishable at all $n$ & $Z_{01}$ \\
$R_{23}$ short & Distinguishable except in the range $n=26-29$ & $Z_{01}(n<26), Z_{14}(n=30)$ \\
$R_{23}$ open & Distinguishable except in the range $n=22-29$ & $Z_{14}$ \\
$X_{C_{30}}$ short & Distinguishable except at $n=30$ & $Z_{14}$ \\
$R_{34}$ short & Distinguishable at all $n$ & $(n=1)$ \\
$R_{34}$ open & Distinguishable except at $n=29$ & $Z_{14}(n=1)$ \\
$X_{C_{40}}$ short & Distinguishable at all $n$ & $Z_{02}(n<29), Z_{14}(n=30)$ \\
\hline
\end{tabular}

TABLE 12: Ambiguity from $\left|Z_{01}\right|$ for three-step RC ladder network.

\begin{tabular}{ll}
\hline Fault & Ambiguity with the following \\
\hline$R_{12}$ short & $X_{C_{20}}$ short $(n=7-9), R_{23}$ short $(n=1), X_{C_{30}}$ short $(n=3)$ \\
$R_{12}$ open & No ambiguity \\
$X_{C_{20}}$ short & $R_{12}$ short $(n=7-9)$ \\
$R_{23}$ short & $R_{12}$ short $(n=1), R_{23}$ open $(n \geq 21), R_{34} \operatorname{short~}(n \geq 27), R_{34}$ open $(n \geq 11), X_{C_{40}}$ short $(n \geq 26)$ \\
$R_{23}$ open & $R_{23}$ short $(n \geq 21), X_{C_{30}}$ short $(n=11-13), R_{34}$ short $(n=14-24), R_{34}$ open $(n \geq 20), X_{C_{40}}$ short $(n \geq 10)$ \\
$X_{C_{30}}$ short & $R_{12}$ short $(n=3), R_{23}$ open $(n=11-13), R_{34}$ short $(n=4, n \geq 23), R_{34}$ open $(n=5), X_{C_{40}}$ short $(n=10-17,23-30)$ \\
$R_{34}$ short & $R_{23}$ short $(n \geq 27), R_{23}$ open $(n=14-24), X_{C_{30}}$ short $(n=4, n \geq 23), X_{C_{40}} \operatorname{short~}(n \geq 15), R_{34}$ open $(n=6,7,30)$ \\
$R_{34}$ open & $R_{23}$ short $(n \geq 11), R_{23}$ open $(n \geq 20), X_{C_{30}} \operatorname{short~}(n=5), R_{34}$ short $(n=6,7,30), X_{C_{40}}$ short $(n \geq 28)$ \\
$X_{C_{40}}$ short & $R_{23}$ short $(n \geq 26), R_{23}$ open $(n \geq 10), X_{C_{30}} \operatorname{short~}(n=10-17,23-30), R_{34}$ short $(n \geq 15), R_{34}$ open $(n \geq 28)$ \\
\hline
\end{tabular}

TABLE 13: Ambiguity from $\left|Z_{02}\right|$ for three-step RC ladder network.

\begin{tabular}{ll}
\hline Fault & Ambiguity with the following \\
\hline$R_{12}$ short & $\begin{array}{l}R_{12} \text { open }(\text { all } n), X_{C_{20}} \text { short }(n \geq 15), R_{23} \text { short }(\text { all } n), R_{23} \text { open, } X_{C_{30}} \text { short }(n \geq 8), R_{34} \text { short }(n=1), R_{34} \text { open } \\
(n=29 \& 30)\end{array}$ \\
& $\begin{array}{l}\left.R_{12} \text { short, } R_{23} \text { short (all } n\right), X_{C_{20}} \text { short }(n \geq 15), R_{23} \text { open, } X_{C_{30}} \text { short }(n \geq 8), R_{34} \text { short }(n=1), R_{34} \text { open } \\
(n=29 \& 30)\end{array}$ \\
$R_{12}$ open & $R_{12}$ short, $R_{12}$ open $(n \geq 15), R_{23}$ short $(n=3 \& \geq 18), R_{23}$ open $(n=5-6 \& \geq 18), X_{C_{30}}$ short $(n \geq 13), R_{34}$ short \\
& $(n=3), R_{34}$ open $(n=29-30)$ \\
$X_{C_{20}}$ short & $R_{12}$ short, $R_{12}$ open $($ all $n), X_{C_{20}}$ short $(n=3 \& \geq 18), R_{23}$ open $(n \geq 11), X_{C_{30}}$ short $(n \geq 7), R_{34}$ short $(n=1-3)$ \\
$R_{23}$ short & $R_{12}$ short, $R_{12}$ open $(n \geq 8), X_{C_{20}}$ short $(n=5-6 \& \geq 18), R_{23}$ short $(n \geq 11), X_{C_{30}}$ short $(n \geq 10)$ \\
$R_{23}$ open & $R_{12}$ short, $R_{12}$ open $(n \geq 8), X_{C_{20}}$ short $(n \geq 13), R_{23}$ short $(n \geq 7), R_{23}$ open $(n \geq 10), R_{34}$ short $(n=6), R_{34}$ open \\
$X_{C_{30}}$ short & $(n \geq 25)$ \\
$R_{34}$ short & $R_{12}$ short, $R_{12}$ open $(n=1), X_{C_{20}}$ short $(n=3), R_{23}$ short $(n=1-3), X_{C_{30}}$ short $(n=6)$ \\
$R_{34}$ open & $R_{12}$ short, $R_{12}$ open $(n=29 \& 30), X_{C_{20}}$ short $(n=29-30), X_{C_{30}}$ short $(n \geq 25)$ \\
$X_{C_{40}}$ short & No ambiguity
\end{tabular}

Tables 20, 21, and 22 show the ambiguity for each fault which is not distinguishable from the measurement of $\left|Z_{01}\right|$, $\left|Z_{02}\right|$, and $\left|Z_{15}\right|$, respectively.

Table 23 gives the conclusion derived from Tables 20, 21, and 22. Figure 17 shows the fault coverage for two-step RC ladder network. For $n=1$ to 12 and 18 to 20 the fault coverage is $100 \%$, but for other values of " $n$ " fault coverage is less than
$100 \%$. From Figure 17, it is also concluded that if we increase the value of " $n$ " above 20 , the fault coverage is decreasing.

\section{Conclusion}

The fault coverage is $100 \%$ for single-step ladder network using only one measurement and fault coverage is $100 \%$ 
TABLE 14: Ambiguity from $\left|Z_{14}\right|$ for three-step RC ladder network.

\begin{tabular}{|c|c|}
\hline Fault & Ambiguity with the following \\
\hline$R_{12}$ short & $R_{23}$ short, $R_{34}$ short $(n=1)$ \\
\hline$R_{12}$ open & No ambiguity \\
\hline$X_{C_{20}}$ short & $R_{23}$ short, $R_{34}$ short $(n=9,10), X_{C_{30}}$ short $(n=1), X_{C_{40}}$ short (all $\left.n\right)$ \\
\hline$R_{23}$ short & $R_{12}$ short $(n=1), R_{23}$ open, $R_{34}$ open $(n \geq 21), R_{34}$ short (all $\left.n\right), X_{C_{20}}$ short, $X_{C_{40}}$ short $(n=9,10)$ \\
\hline$R_{23}$ open & $R_{23}$ short, $R_{34}$ short $(n \geq 21), R_{34}$ open (all $\left.n\right), X_{C_{30}}$ short $(n=11,12)$ \\
\hline$X_{C_{30}}$ short & $X_{C_{20}}$ short, $X_{C_{40}}$ short $(n=1), R_{23}$ open, $R_{34}$ open $(n=11,12)$ \\
\hline$R_{34}$ short & $R_{12}$ short $(n=1), R_{23}$ open, $R_{34}$ open $(n \geq 21), R_{23}$ short (all $\left.n\right), X_{C_{20}}$ short, $X_{C_{40}}$ short $(n=9,10)$ \\
\hline$R_{34}$ open & $R_{23}$ short, $R_{34}$ short $(n \geq 21), R_{23}$ open (all $\left.n\right), X_{C_{30}}$ short $(n=11,12)$ \\
\hline$X_{C_{40}}$ short & $R_{23}$ short, $R_{34}$ short $(n=9,10), X_{C_{30}}$ short $(n=1), X_{C_{20}}$ short (all $\left.n\right)$ \\
\hline
\end{tabular}

TABLE 15: Ambiguity from $\left|Z_{01}\right|,\left|Z_{02}\right|$, and $\left|Z_{14}\right|$ for three-step RC ladder network.

\begin{tabular}{ll}
\hline Fault & Ambiguity with the following \\
\hline$R_{12}$ short & $R_{23}$ short $(n=1)$ \\
$R_{12}$ open & No ambiguity \\
$X_{C_{20}}$ short & No ambiguity \\
$R_{23}$ short & $R_{12}$ short $(n=1), R_{23}$ open $(n \geq 21)$ \\
$R_{23}$ open & $R_{23}$ short $(n \geq 21), X_{C_{30}}$ short $(n=11,12)$ \\
$X_{C_{30}}$ short & $R_{23}$ open $(n=11,12)$ \\
$R_{34}$ short & No ambiguity \\
$R_{34}$ open & No ambiguity \\
$X_{C_{40}}$ short & No ambiguity \\
\hline
\end{tabular}

TABLE 16: $\left|Z_{01}\right|^{2}$ expression for four-step RC ladder network.

\begin{tabular}{lcc}
\hline Fault location & Short fault $\left|Z_{01}\right|^{2}$ & Open fault $\left|Z_{01}\right|^{2}$ \\
$R_{12}$ & $\frac{\left[a^{5}+11 a^{3}+14 a\right]^{2}+\left[a^{6}+14 a^{4}+34 a^{2}+4\right]^{2}}{\omega^{2} n^{2} C^{2}\left[a^{6}+16 a^{4}+148 a^{2}+16\right]^{2}}$ & Infinity \\
$X_{C_{20}}$ & $\frac{\left[4 a^{5}+34 a^{3}+21 a\right]^{2}+\left[2 a^{4}+15 a^{2}+4\right]^{2}}{\omega^{2} n^{2} C^{2}\left[4 a^{4}+65 a^{2}+16\right]^{2}}$ & None \\
$R_{23}$ & $\frac{a^{6}+5 a^{4}+4 a^{2}}{\omega^{2} n^{2} C^{2}\left[a^{4}+2 a^{2}+1\right]}$ & $\frac{a^{2}+1}{\omega^{2} n^{2} C^{2}}$ \\
$X_{C_{30}}$ & $\frac{\left[4 a^{5}+24 a^{3}+26 a\right]^{2}+\left[4 a^{4}+14 a^{2}+4\right]^{2}}{\omega^{2} n^{2} C^{2}\left[4 a^{4}+20 a^{2}+16\right]^{2}}$ & None \\
$R_{34}$ & $\frac{a^{10}+17 a^{8}+80 a^{6}+73 a^{4}+9 a^{2}}{\omega^{2} n^{2} C^{2}\left[a^{8}+14 a^{6}+51 a^{4}+14 a^{2}+1\right]}$ & $\frac{a^{6}+11 a^{4}+29 a^{2}+4}{\omega^{2} n^{2} C^{2}\left[a^{4}+8 a^{2}+16\right]}$ \\
$X_{C_{40}}$ & $\frac{\left[4 a^{5}+37 a^{3}+29 a\right]^{2}+\left[4 a^{4}+25 a^{2}+4\right]^{2}}{\omega^{2} n^{2} C^{2}\left[4 a^{4}+33 a^{2}+16\right]^{2}}$ & None \\
$R_{45}$ & $\frac{\left[a^{7}+14 a^{5}+34 a^{3}+4 a\right]^{2}+\left[a^{6}+11 a^{4}+14 a^{2}\right]^{2}}{\omega^{2} n^{2} C^{2}\left[a^{6}+13 a^{4}+26 a^{2}+1\right]^{2}}$ & $\omega^{2} n^{2} C^{2}\left[a^{4}+10 a^{2}+9\right]^{2}$ \\
$X_{C_{50}}$ & None
\end{tabular}


TABLE 17: $\left|Z_{02}\right|^{2}$ expression for four-step RC ladder network.

\begin{tabular}{lcc}
\hline Fault location & Short fault $\left|Z_{02}\right|^{2}$ & Open fault $\left|Z_{02}\right|^{2}$ \\
$R_{12}$ & $\frac{\left[a^{5}+11 a^{3}+14 a\right]^{2}+\left[a^{6}+14 a^{4}+34 a^{2}+4\right]^{2}}{\omega^{2} n^{2} C^{2}\left[a^{6}+16 a^{4}+52 a^{2}+16\right]^{2}}$ & None \\
$X_{C_{20}}$ & $\frac{\left[a^{5}+8 a^{3}+3 a\right]^{2}+\left[a^{6}+11 a^{4}+14 a^{2}\right]^{2}}{\omega^{2} n^{2} C^{2}\left[a^{6}+13 a^{4}+26 a^{2}+1\right]^{2}}$ & $\omega^{2} n^{2} C^{2}\left[a^{6}+16 a^{4}+52 a^{2}+16\right]^{2}$ \\
$R_{23}$ & $\frac{\left[4 a^{3}+13 a\right]^{2}+\left[4 a^{4}+25 a^{2}+4\right]^{2}}{\omega^{2} n^{2} C^{2}\left[4 a^{4}+33 a^{2}+16\right]^{2}}$ & $\frac{\left[a^{3}+5 a\right]^{2}+\left[a^{4}+8 a^{2}+3\right]^{2}}{\omega^{2} n^{2} C^{2}\left[a^{4}+10 a^{2}+9\right]^{2}}$ \\
$X_{C_{30}}$ & $\frac{a^{8}+11 a^{6}+29 a^{4}+4 a^{2}}{\omega^{2} n^{2} C^{2}\left[a^{8}+14 a^{6}+51 a^{4}+14 a^{2}+1\right]}$ & None \\
$R_{34}$ & $\frac{\left[4 a^{3}+10 a\right]^{2}+\left[4 a^{4}+14 a^{2}+4\right]^{2}}{\omega^{2} n^{2} C^{2}\left[4 a^{4}+20 a^{2}+16\right]^{2}}$ & $\frac{a^{4}+5 a^{2}+4}{a^{2} n^{2} C^{2}\left[a^{4}+8 a^{2}+16\right]}$ \\
$X_{C_{40}}$ & $\frac{a^{4}+a^{2}}{\omega^{2} n^{2} C^{2}\left[a^{4}+2 a^{2}+1\right]}$ & None \\
$R_{45}$ & $\frac{\left[a^{3}+5 a\right]^{2}+\left[2 a^{4}+15 a^{2}+4\right]^{2}}{\omega^{2} n^{2} C^{2}\left[4 a^{4}+33 a^{2}+16\right]^{2}}$ & 1 \\
$X_{C_{50}}$ & 0 & $\frac{\omega^{2} n^{2} C^{2}}{\text { None }}$
\end{tabular}

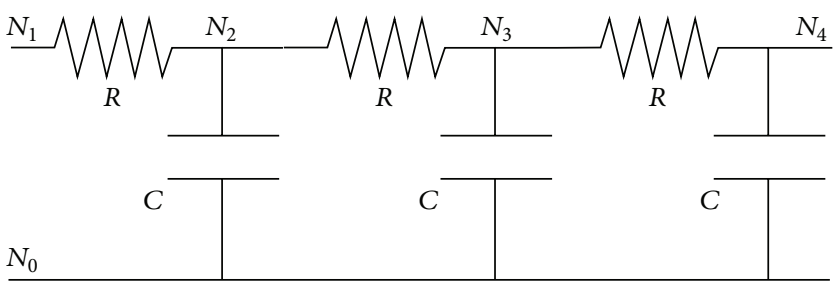

Figure 8: Three-step RC ladder network.

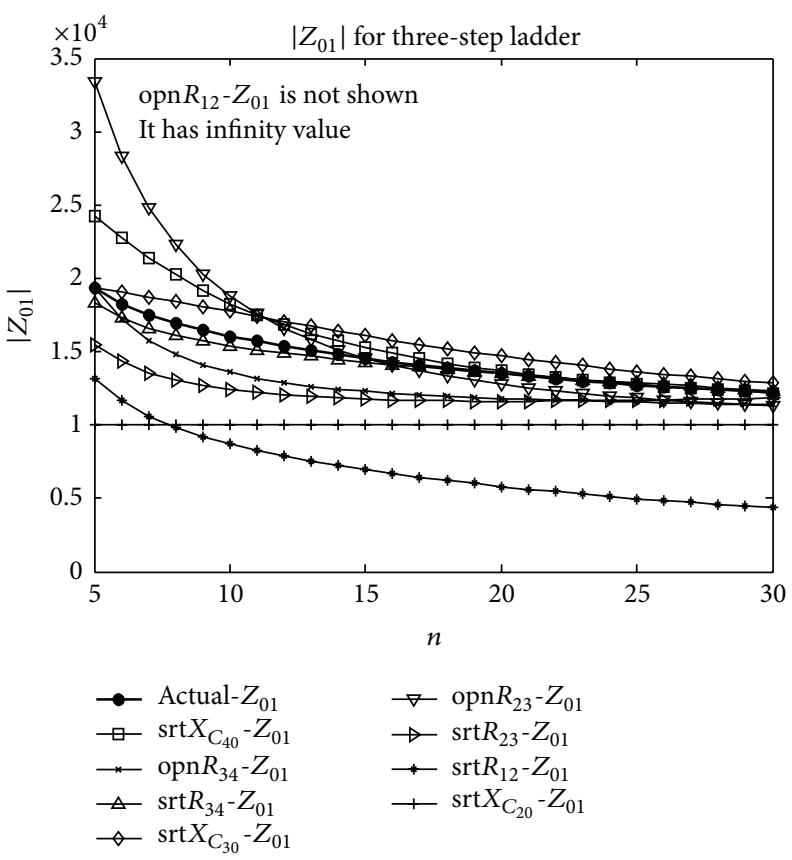

FIgURE 9: Plot of $\left|Z_{01}\right|$ versus " $n$ " for different faults of three-step network. 


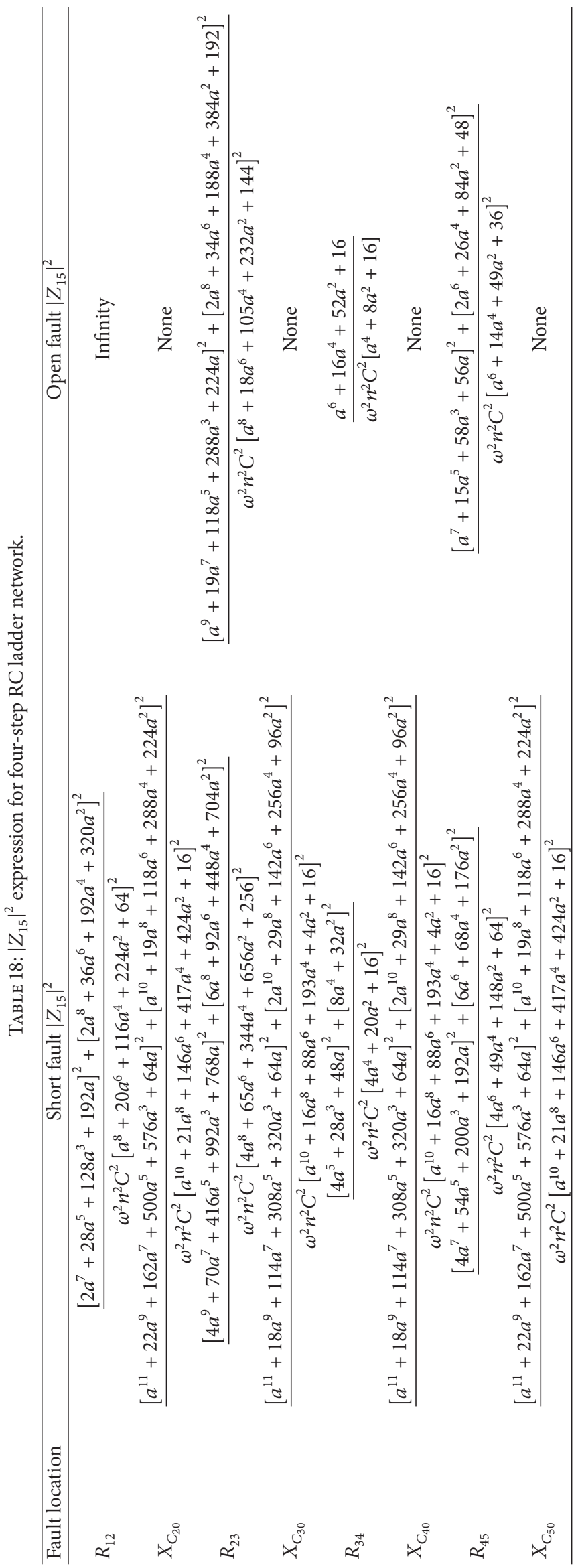


TABLE 19: Distinguishability for four-step RC ladder network.

\begin{tabular}{lcc}
\hline Fault type & Distinguishability & By measuring \\
\hline$R_{12}$ short & Distinguishable at all $n$ & $Z_{01}$ or $Z_{15}$ \\
$R_{12}$ open & Distinguishable at all $n$ & $Z_{01}$ or $Z_{15}$ \\
$X_{C_{20}}$ short & Distinguishable at all $n$ & $Z_{01}$ or $Z_{15}$ \\
$R_{23}$ short & Distinguishable at all $n$ & $Z_{01}$ or $Z_{15}$ \\
$R_{23}$ open & Distinguishable except at $n=29,30$ & $Z_{01}(n=8,9), Z_{15}($ all other $n)$ \\
$X_{C_{30}}$ short & Distinguishable except at $n=30$ & $Z_{15}$ \\
$R_{34}$ short & Distinguishable except for $n \geq 13$ & $Z_{15}$ \\
$R_{34}$ open & Distinguishable except at $n=30$ & $Z_{02}(n=5), Z_{15}($ all other $n)$ \\
$X_{C_{40}}$ short & Distinguishable except at $n=30$ & $Z_{15}$ \\
$R_{45}$ short & Distinguishable at all $n$ & $Z_{02}$ or $Z_{15}$ \\
$R_{45}$ open & Distinguishable except at $n=30$ & $Z_{02}$ \\
$X_{C_{50}}$ short & Distinguishable at all $n$ & $Z_{02}$ or $Z_{15}$ \\
\hline
\end{tabular}

TABLE 20: Ambiguity from $\left|Z_{01}\right|$ for four-step RC ladder network.

\begin{tabular}{ll}
\hline Fault & Ambiguity with the following \\
\hline$R_{12}$ short & $X_{C_{20}}$ short $(n=5)$ \\
$R_{12}$ open & No ambiguity \\
$X_{C_{20}}$ short & $R_{12}$ short $(n=5), R_{23}$ short $(n=8-10)$ \\
$R_{23}$ short & $X_{C_{20}}$ short $(n=8-10)$ \\
& $X_{C_{30}}$ short $(n=11,12), R_{34}$ short $(n=13-20), R_{34}$ open $(n \geq 15), X_{C_{40}}$ short $(n \geq 10), R_{45}$ short, $X_{C_{50}}$ short \\
$R_{23}$ open & $(n \geq 12), R_{45}$ open $(n \geq 13)$ \\
& $R_{23}$ open $(n=11,12), R_{34}$ short $(n=4,5 \& \geq 20), R_{34}$ open $(n=6,29,30), X_{C_{40}}$ short $(n=10-17 \& \geq 22), R_{45}$ \\
$X_{C_{30}}$ short & short $(n=5-10 \& \geq 23), R_{45}$ open $(n=5,6 \& \geq 23), X_{C_{50}}$ short $(n=8-11 \& \geq 25)$ \\
& $R_{23}$ open $(n=13-20), X_{C_{30}}$ short $(n=4,5 \& \geq 20), R_{34}$ open $(n=6-9 \& \geq 19), X_{C_{40}}$ short $(n \geq 13), R_{45}$ short \\
$R_{34}$ short & $(n \geq 9), R_{45}$ open $(n \geq 5), X_{C_{50}}$ short $(n \geq 10)$ \\
& $R_{23}$ open $(n \geq 15), X_{C_{30}}$ short $(n=6,29,30), R_{34}$ short $(n=6-9 \& \geq 19), X_{C_{40}}$ short $(n \geq 19), R_{45}$ short $(n=5$, \\
$R_{34}$ open & $6 \& \geq 18), R_{45}$ open $(n=6-9, \& \geq 15), X_{C_{50}}$ short $(n=3 \& \geq 16)$ \\
& $R_{23}$ open $(n \geq 10), X_{C_{30}}$ short $(n=10-17 \& \geq 22), R_{34}$ short $(n \geq 13), R_{34}$ open $(n \geq 19), R_{45}$ short $(n \geq 12), R_{45}$ \\
$X_{C_{40}}$ short & open $(n \geq 14), X_{C_{50}}$ short $(n=5,6 \& \geq 12)$ \\
& $R_{23}$ open $(n \geq 12), X_{C_{30}}$ short $(n=5-10 \& \geq 23), R_{34}$ short $(n \geq 9), R_{34}$ open $(n=5,6 \& \geq 18), X_{C_{40}}$ short \\
$R_{45}$ short & $(n \geq 12), R_{45}$ open $(n \geq 3), X_{C_{50}}$ short $(n \geq 9)$ \\
& $R_{23}$ open $(n \geq 13), X_{C_{30}}$ short $(n=5,6 \& \geq 23), R_{34}$ short $(n \geq 5), R_{34}$ open $(n=6-9, \& \geq 15), X_{C_{40}}$ short \\
$R_{45}$ open & $(n \geq 14), R_{45}$ short $(n \geq 3), X_{C_{50}}$ short $(n \geq 11)$ \\
& $R_{23}$ open $(n \geq 12), X_{C_{30}}$ short $(n=8-11 \& \geq 25), R_{34}$ short $(n \geq 10), R_{34}$ open $(n=3 \& \geq 16), X_{C_{40}}$ short $(n=5$, \\
& $6 \& \geq 12), R_{45}$ short $(n \geq 9), R_{45}$ open $(n \geq 11)$ \\
$X_{C_{50}}$ short & \\
\hline
\end{tabular}

except for $n=1$ for two-step ladder network. But these have high area overhead which is a costly requirement for integrated circuit manufacturing. From Figures 12 and 17, it is shown that, for " $n$ " ranging from 1 to 12 , the four-step option is a better choice, and for " $n$ " ranging from 13 to 30 , the three-step option is a better choice. It has been concluded that only three measurements are required in different step size networks except single-step networks.

\section{Notations}

Actual- $Z_{01}:\left|Z_{01}\right|^{2}$ when there is no fault in the network $\operatorname{srt} R_{i j}-Z_{01}: \quad\left|Z_{01}\right|^{2}$ when $R_{i j}$ is short circuit $\operatorname{opn} R_{i j}-Z_{01}:\left|Z_{01}\right|^{2}$ when $R_{i j}$ is open circuit $\operatorname{srt} X_{C_{i j}}-Z_{01}:\left|Z_{01}\right|^{2}$ when $X_{C_{i j}}$ is short circuit
Actual- $Z_{L L}:\left|Z_{L L}\right|^{2}$ when there is no fault in the network $\operatorname{srt} R_{i j}-Z_{L L}: \quad\left|Z_{L L}\right|^{2}$ when $R_{i j}$ is short circuit opn $R_{i j}-Z_{L L}:\left|Z_{L L}\right|^{2}$ when $R_{i j}$ is open circuit $\operatorname{srt} X_{C_{i j}}-Z_{L L}:\left|Z_{L L}\right|^{2}$ when $X_{C_{i j}}$ is short circuit Actual- $Z_{1 L}:\left|Z_{1 L}\right|^{2}$ when there is no fault in the network $\operatorname{srt} R_{i j}-Z_{1 L}: \quad\left|Z_{1 L}\right|^{2}$ when $R_{i j}$ is short circuit opn $R_{i j}-Z_{1 L}:\left|Z_{1 L}\right|^{2}$ when $R_{i j}$ is open circuit $\operatorname{srt} X_{C_{i j}}-Z_{1 L}:\left|Z_{1 L}\right|^{2}$ when $X_{C_{i j}}$ is short circuit.

\section{Symbols}

$R_{i j}$ : The resistance between nodes $i$ and $j$

$X_{C_{i j}}$ : The impedance due to capacitor between nodes $i$ and $j$. 
TABLE 21: Ambiguity from $\left|Z_{02}\right|$ for four-step RC ladder network.

\begin{tabular}{|c|c|}
\hline Fault & Ambiguity with the following \\
\hline$R_{12}$ short & $\begin{array}{l}R_{12} \text { open }(\text { all } n), X_{C_{20}} \text { short }(n \geq 9), R_{23} \text { short }(\text { all } n), R_{23} \text { open }(n \geq 4), X_{C_{30}} \text { short }(n=3 \& \geq 12), R_{34} \text { short } \\
(n \geq 12), R_{34} \text { open }(n \geq 7), X_{C_{40}} \text { short }(n \geq 10), R_{45} \text { open }(n=30)\end{array}$ \\
\hline$R_{12}$ open & $\begin{array}{l}R_{12} \text { short }(\text { all } n), X_{C_{20}} \text { short }(n \geq 9), R_{23} \text { short }(\text { all } n), R_{23} \text { open }(n \geq 4), X_{C_{30}} \text { short }(n=3 \& \geq 12), R_{34} \text { short } \\
(n \geq 12), R_{34} \text { open }(n \geq 7), X_{C_{40}} \text { short }(n \geq 10), R_{45} \text { open }(n=30)\end{array}$ \\
\hline$X_{C_{20}}$ short & $\begin{array}{l}R_{12} \text { short, } R_{12} \text { open }(n \geq 9), R_{23} \text { short }(n \geq 10), R_{23} \text { open, } X_{C_{40}} \text { short }(n \geq 12), X_{C_{30}} \text { short, } R_{34} \text { open }(n \geq 5), R_{34} \\
\text { short }(n \geq 13), R_{45} \text { open }(n=30)\end{array}$ \\
\hline$R_{23}$ short & $\begin{array}{l}\left.R_{12} \text { short, } R_{12} \text { open (all } n\right), X_{C_{20}} \text { short, } X_{C_{40}} \text { short }(n \geq 10), R_{23} \text { open }(n \geq 5), X_{C_{30}} \text { short, } R_{34} \text { short }(n \geq 12), R_{34} \\
\text { open }(n \geq 8), R_{45} \text { open }(n=30)\end{array}$ \\
\hline$R_{23}$ open & $\begin{array}{l}R_{12} \text { short, } R_{12} \text { open }(n \geq 4), X_{C_{20}} \text { short }(n \geq 12), R_{23} \text { short }(n \geq 5), X_{C_{30}} \text { short }(n \geq 15), R_{34} \text { short, } R_{34} \text { open, } X_{C_{40}} \\
\text { short }(n \geq 8), R_{45} \text { open }(n=30)\end{array}$ \\
\hline$X_{C_{30}}$ short & $\begin{array}{l}R_{12} \text { short, } R_{12} \text { open }(n=3 \& \geq 12), X_{C_{20}} \text { short }(n \geq 5), R_{23} \text { short }(n \geq 12), R_{23} \text { open }(n \geq 15), R_{34} \text { short }(n \geq 16) \text {, } \\
R_{34} \text { open }(n=5,6 \& \geq 18), X_{C_{40}} \text { short }(n \geq 14), R_{45} \text { open }(n=29,30)\end{array}$ \\
\hline$R_{34}$ short & $\begin{array}{l}R_{12} \text { short, } R_{12} \text { open, } R_{23} \text { short }(n \geq 12), X_{C_{20}} \text { short }(n \geq 13), R_{23} \text { open }(n \geq 8), X_{C_{30}} \text { short }(n \geq 16), R_{34} \text { open } \\
(n \geq 10), X_{C_{40}} \text { short }(n \geq 6), R_{45} \text { open }(n=29,30)\end{array}$ \\
\hline$R_{34}$ open & $\begin{array}{l}R_{12} \text { short, } R_{12} \text { open }(n \geq 7), X_{C_{20}} \text { short }(n \geq 5), R_{23} \text { short, } R_{23} \text { open }(n \geq 8), X_{C_{30}} \text { short }(n=5,6 \& \geq 18), R_{34} \\
\text { short, } X_{C_{40}} \text { short }(n \geq 10)\end{array}$ \\
\hline$X_{C_{40}}$ short & $\begin{array}{l}R_{12} \text { short, } R_{12} \text { open, } R_{23} \text { short, } R_{34} \text { open }(n \geq 10), X_{C_{20}} \text { short }(n \geq 12), R_{23} \text { open }(n \geq 8), X_{C_{30}} \text { short }(n \geq 14), R_{34} \\
\text { short }(n \geq 6), R_{45} \text { short }(n=5), R_{45} \text { open }(n \geq 25)\end{array}$ \\
\hline$R_{45}$ short & $X_{C_{40}}$ short $(n=5)$ \\
\hline$R_{45}$ open & $\begin{array}{l}R_{12} \text { short, } R_{12} \text { open, } X_{C_{20}} \text { short, } R_{23} \text { short, } R_{23} \text { open }(n=30), X_{C_{30}} \text { short, } R_{34} \text { short }(n=29,30), X_{C_{40}} \text { short } \\
(n \geq 25)\end{array}$ \\
\hline$X_{C_{50}}$ short & No ambiguity \\
\hline
\end{tabular}

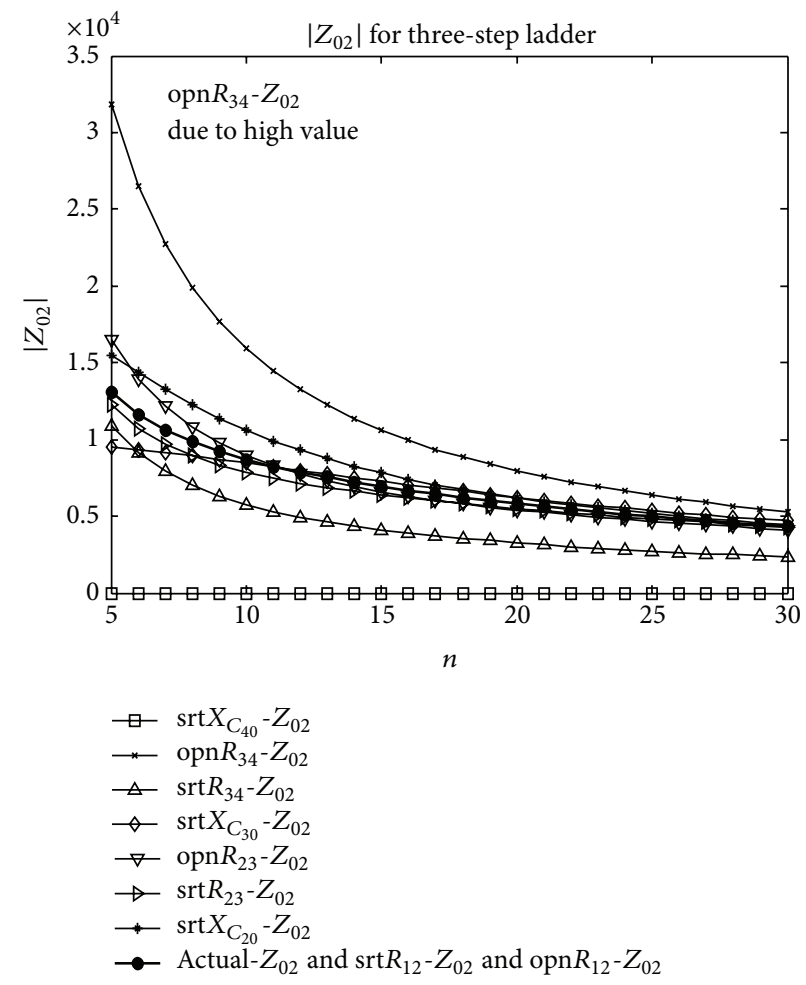

FIGURE 10: Plot of $\left|Z_{02}\right|$ versus " $n$ " for different faults of three-step network. 


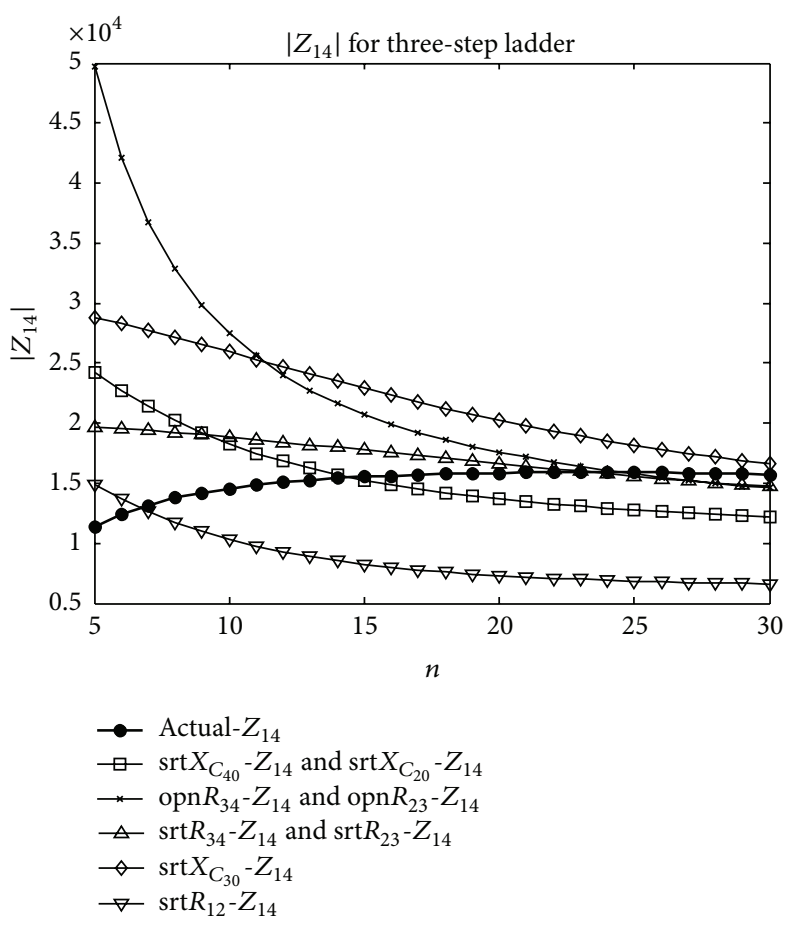

FIGURE 11: Plot of $\left|Z_{14}\right|$ versus " $n$ " for different faults of three-step network.

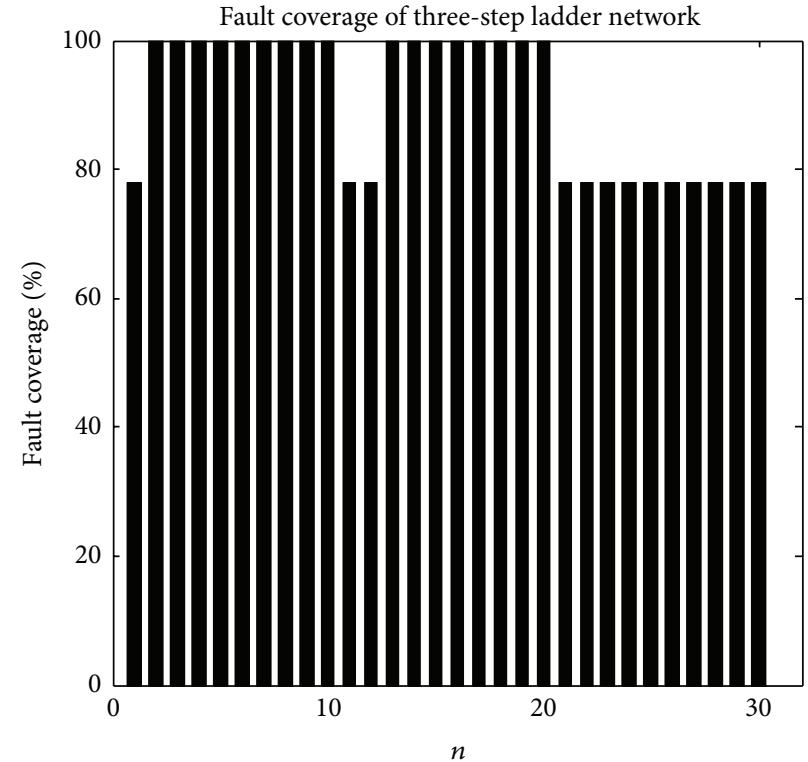

FIGURE 12: Fault coverage for three-step RC ladder network.

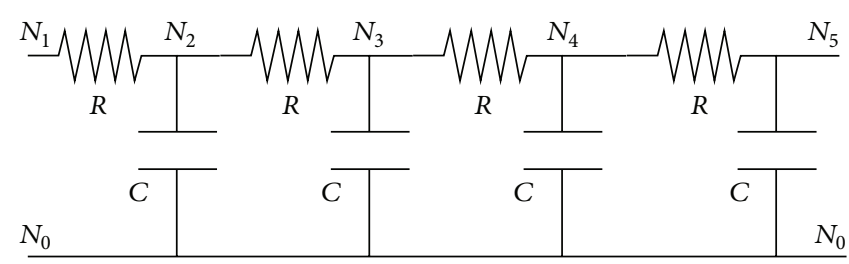

FIGURE 13: Four-step RC ladder network. 
TABLE 22: Ambiguity from $\left|Z_{15}\right|$ for four-step RC ladder network.

\begin{tabular}{|c|c|}
\hline Fault & Ambiguity with the following \\
\hline$R_{12}$ short & $X_{C_{20}}$ short, $X_{C_{50}}$ short $(n=4,6-21), R_{23}$ short, $R_{45}$ short $(n=1-4), R_{34}$ short $(n=1-3)$ \\
\hline$R_{12}$ open & No ambiguity \\
\hline$X_{C_{20}}$ short & $R_{12}$ short $(n=4,6-21), R_{34}$ short $(n=3), X_{C_{50}}$ short (all $\left.n\right)$ \\
\hline$R_{23}$ short & $\begin{array}{l}R_{12} \text { short }(n=1-4), R_{23} \text { open, } R_{45} \text { open }(n \geq 18), R_{34} \text { short }(n=1-5), R_{34} \text { open }(n=8-10, \& \geq 16), R_{45} \text { short (all } \\
n)\end{array}$ \\
\hline$R_{23}$ open & $R_{23}$ short, $R_{45}$ short $(n \geq 18), R_{34}$ short $(n=11-13), R_{34}$ open $(n \geq 21), R_{45}$ open (all $\left.n\right)$ \\
\hline$X_{C_{30}}$ short & $R_{34}$ short $(n \geq 26), R_{34}$ open $(n=3), X_{C_{40}}$ short (all $\left.n\right)$ \\
\hline$R_{34}$ short & $\begin{array}{l}R_{12} \text { short }(n=1-3), R_{34} \text { open }(n=7), X_{C_{20}} \text { short, } X_{C_{50}} \text { short }(n=3), R_{23} \text { short, } R_{45} \text { short }(n=1-5), R_{23} \text { open, } \\
R_{45} \text { open }(n=11-13), X_{C_{30}} \text { short, } X_{C_{40}} \text { short }(n \geq 26)\end{array}$ \\
\hline$R_{34}$ open & $\begin{array}{l}R_{23} \text { short, } R_{45} \text { short }(n=8-10 \& \geq 16), R_{23} \text { open, } R_{45} \text { open }(n \geq 21), X_{C_{30}} \text { short, } X_{C_{40}} \text { short }(n=3), R_{34} \text { short } \\
(n=7)\end{array}$ \\
\hline$X_{C_{40}}$ short & $R_{34}$ short $(n \geq 26), R_{34}$ open $(n=3), X_{C_{30}}$ short $($ all $n)$ \\
\hline$R_{45}$ short & $\begin{array}{l}R_{12} \text { short }(n=1-4), R_{23} \text { open, } R_{45} \text { open }(n \geq 18), R_{34} \text { short }(n=1-5), R_{34} \text { open }(n=8-10 \& \geq 16), R_{23} \text { short (all } \\
n)\end{array}$ \\
\hline$R_{45}$ open & $R_{23}$ short, $R_{45}$ short $(n \geq 18), R_{34}$ short $(n=11-13), R_{34}$ open $(n \geq 21), R_{23}$ open (all $\left.n\right)$ \\
\hline$X_{C_{50}}$ short & $R_{12}$ short $(n=4,6-21), R_{34}$ short $\left.(n=3), X_{C_{20}} \operatorname{short~(all~} n\right)$ \\
\hline
\end{tabular}

TABLE 23: Ambiguity from $\left|Z_{01}\right|,\left|Z_{02}\right|$, and $\left|Z_{15}\right|$ for four-step RC ladder network.

\begin{tabular}{ll}
\hline Fault & Ambiguity with the following \\
\hline$R_{12}$ short & No ambiguity \\
$R_{12}$ open & No ambiguity \\
$X_{C_{20}}$ short & No ambiguity \\
$R_{23}$ short & No ambiguity \\
$R_{23}$ open & $R_{34}$ short $(n=13), R_{34}$ open $(n \geq 21), R_{45}$ open $(n=30)$ \\
$X_{C_{30}}$ short & $R_{34}$ short $(n \geq 26), X_{C_{40}}$ short $(n=14-17 \& \geq 22)$ \\
$R_{34}$ short & $R_{23}$ open $(n=13), X_{C_{30}}$ short, $X_{C_{40}}$ short $(n \geq 26)$ \\
$R_{34}$ open & $R_{23}$ open $(n \geq 21)$ \\
$X_{C_{40}}$ short & $X_{C_{30}}$ short $(n=14-17 \& \geq 22), R_{34}$ short $(n \geq 26)$ \\
$R_{45}$ short & No ambiguity \\
$R_{45}$ open & $R_{23}$ open $(n=30)$ \\
$X_{C_{50}}$ short & No ambiguity \\
\hline
\end{tabular}

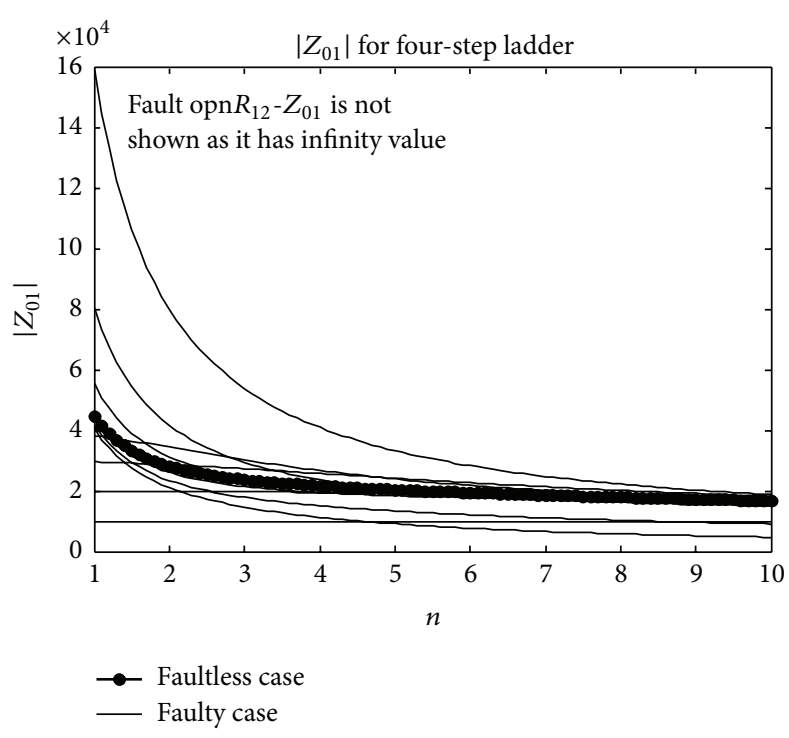

FIGURE 14: Plot of $\left|Z_{01}\right|$ versus " $n$ " for different faults of four-step network. 


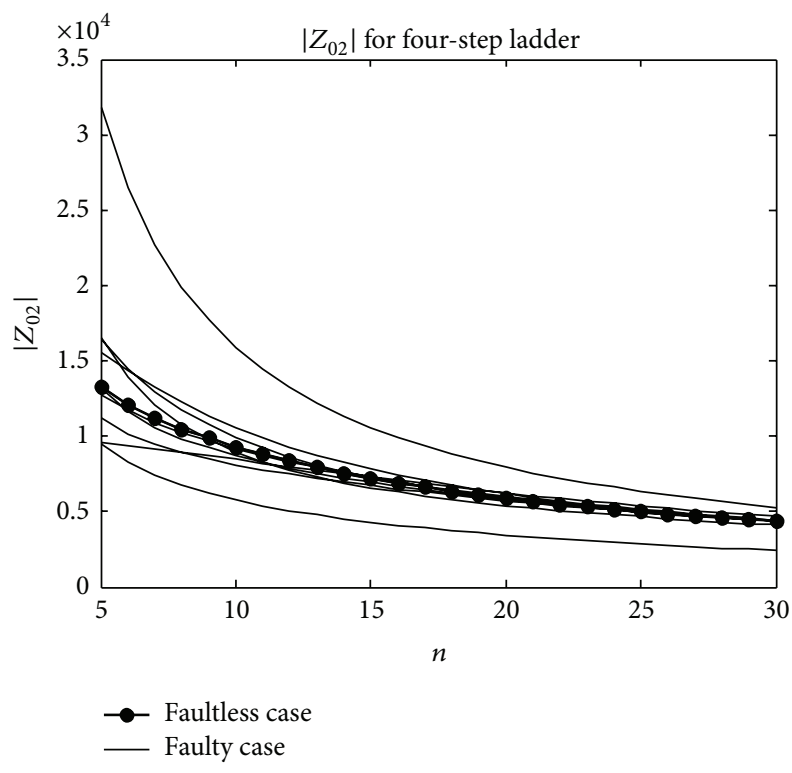

FIGURE 15: Plot of $\left|Z_{02}\right|$ versus " $n$ " for different faults of four-step network.

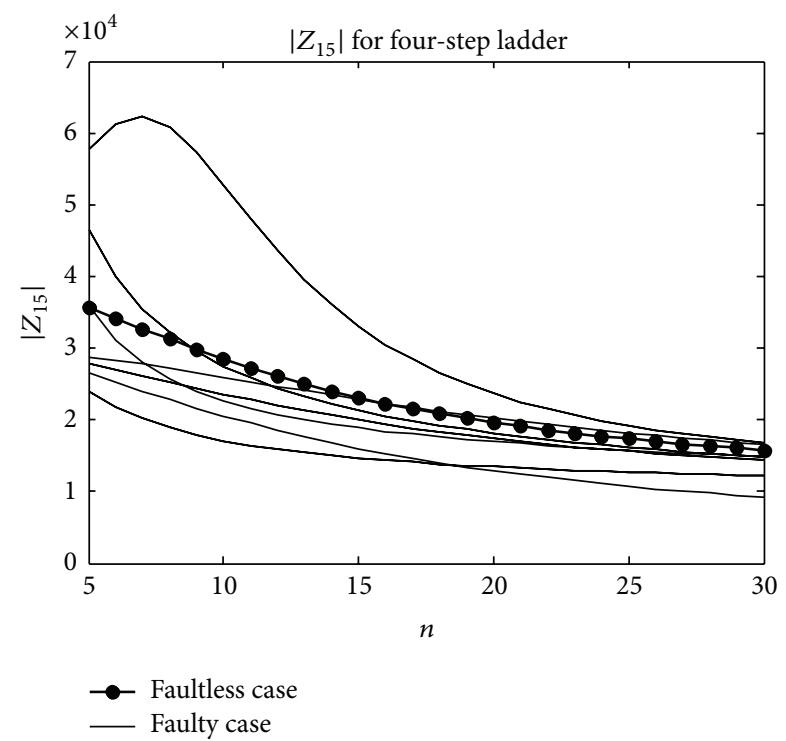

Figure 16: Plot of $\left|Z_{15}\right|$ versus " $n$ " for different faults of four-step network.

\section{Subscripts}

$i$ and $j:$ The node numbers

$L$ : $\quad$ The last node number in the RC circuit.

\section{Competing Interests}

The authors declare that they have no competing interests.

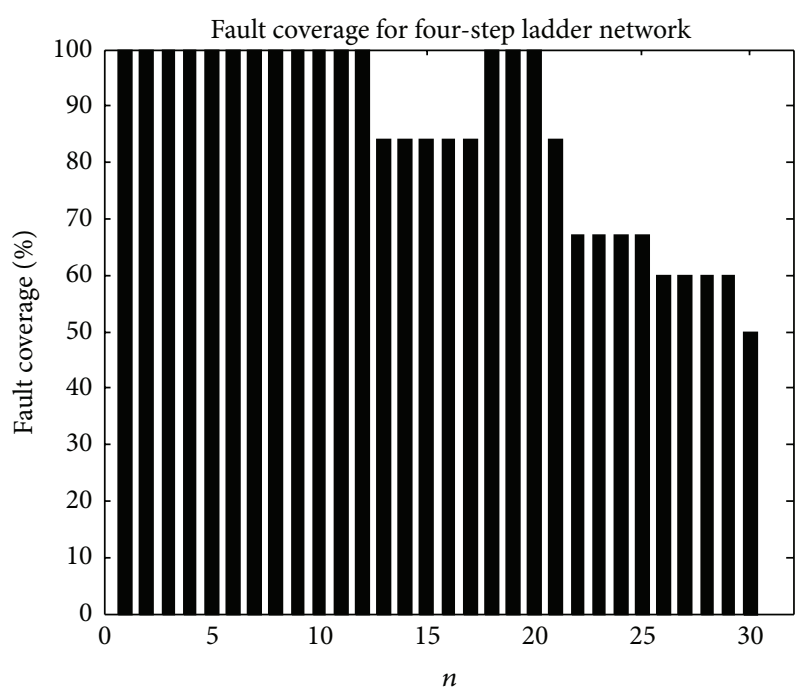

FIGURE 17: Fault coverage for four-step RC ladder network.

\section{References}

[1] S. B. Shashank, M. Wajid, and S. Mandavalli, "Fault detection in resistive ladder network with minimal measurements," Microelectronics Reliability, vol. 52, no. 8, pp. 1586-1592, 2012.

[2] G. Prabhavathi and V. Ramachandran, "High-Q resistancecapacitance ladder phase-shift networks," IEEE Transactions on Circuit Theory, vol. 14, no. 2, pp. 148-153, 1967.

[3] R. A. Stein and A. I. Salama, "Resistance and capacitance minimization in low-pass RC ladder networks," IEEE Transactions on Circuits and Systems, vol. CAS-22, pp. 27-32, 1975.

[4] K. Huang, H.-G. Stratigopoulos, and S. Mir, "Fault diagnosis of analog circuits based on machine learning," in Proceedings of the Design, Automation \& Test in Europe Conference \& Exhibition (DATE '10), pp. 1761-1766, IEEE, Dresden, Germany, March 2010.

[5] P. Kyzioł, D. Grzechca, and J. Rutkowski, "Multidimensional search space for catastrophic faults diagnosis in analog electronic circuits," in Proceedings of the European Conference on Circuit Theory and Design (ECCTD '09), pp. 555-558, IEEE, Antalya, Turkey, August 2009.

[6] J. A. Starzyk, D. Liu, Z.-H. Liu, D. E. Nelson, and J. O. Rutkowski, "Entropy-based optimum test points selection for analog fault dictionary techniques," IEEE Transactions on Instrumentation and Measurement, vol. 53, no. 3, pp. 754-761, 2004.

[7] K. Huang, H.-G. Stratigopoulos, S. Mir, C. Hora, Y. Xing, and B. Kruseman, "Diagnosis of local spot defects in analog circuits," IEEE Transactions on Instrumentation and Measurement, vol. 61, no. 10, pp. 2701-2712, 2012.

[8] E. McShane, K. Shenai, L. Alkalai et al., "Novel design for testability of a mixed-signal VLSIC," in Proceedings of the 9th Great Lakes Symposium on VLSI (GLSVLSI '99), pp. 97-100, Ypsilanti, Mich, USA, March 1999.

[9] H. Tang and R. J. Mack, "Multiple fault location in linear circuits via multiple excitations," in Proceedings of the IEEE International Symposium on Circuits and Systems, pp. 29-32, New Orleans, La, USA, May 1990. 


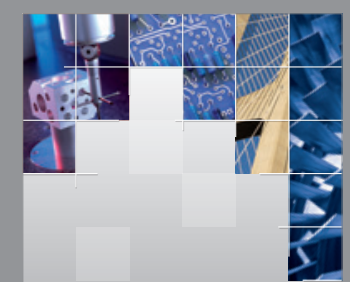

\section{Enfincering}
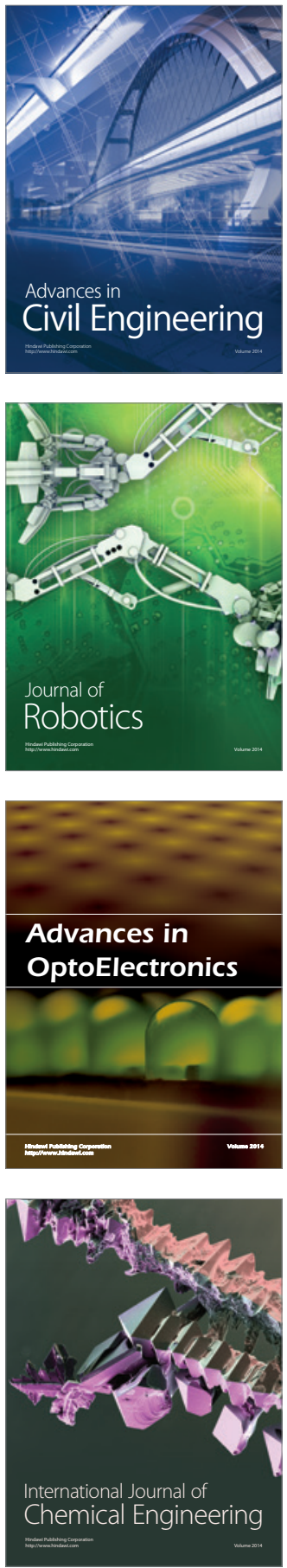

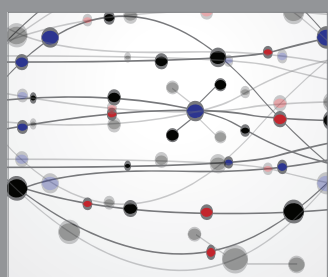

The Scientific World Journal

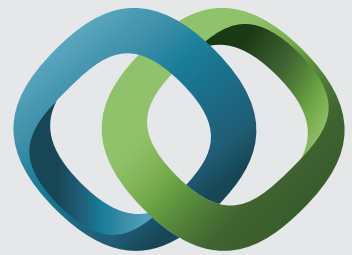

\section{Hindawi}

Submit your manuscripts at

http://www.hindawi.com
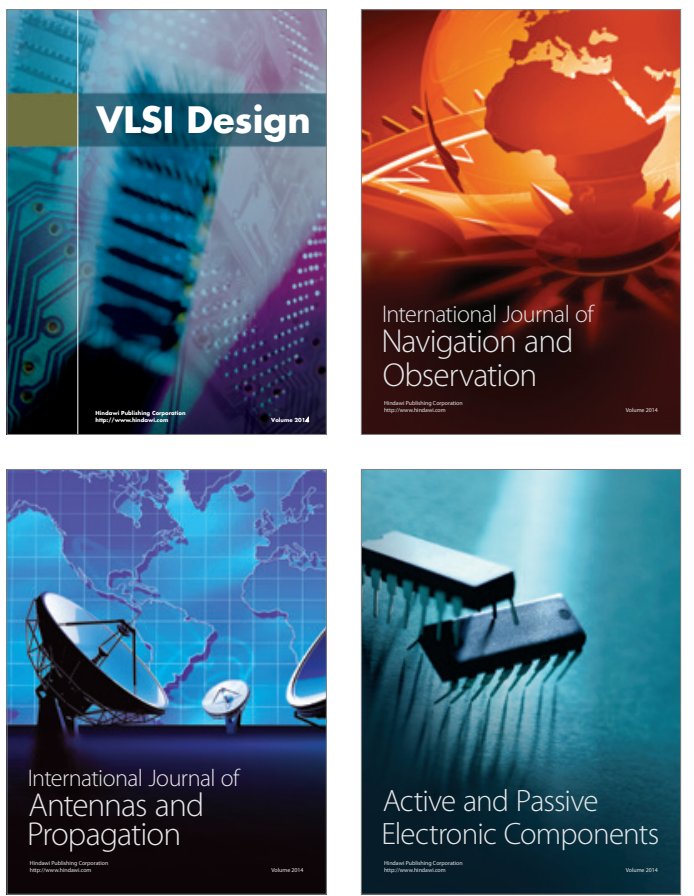
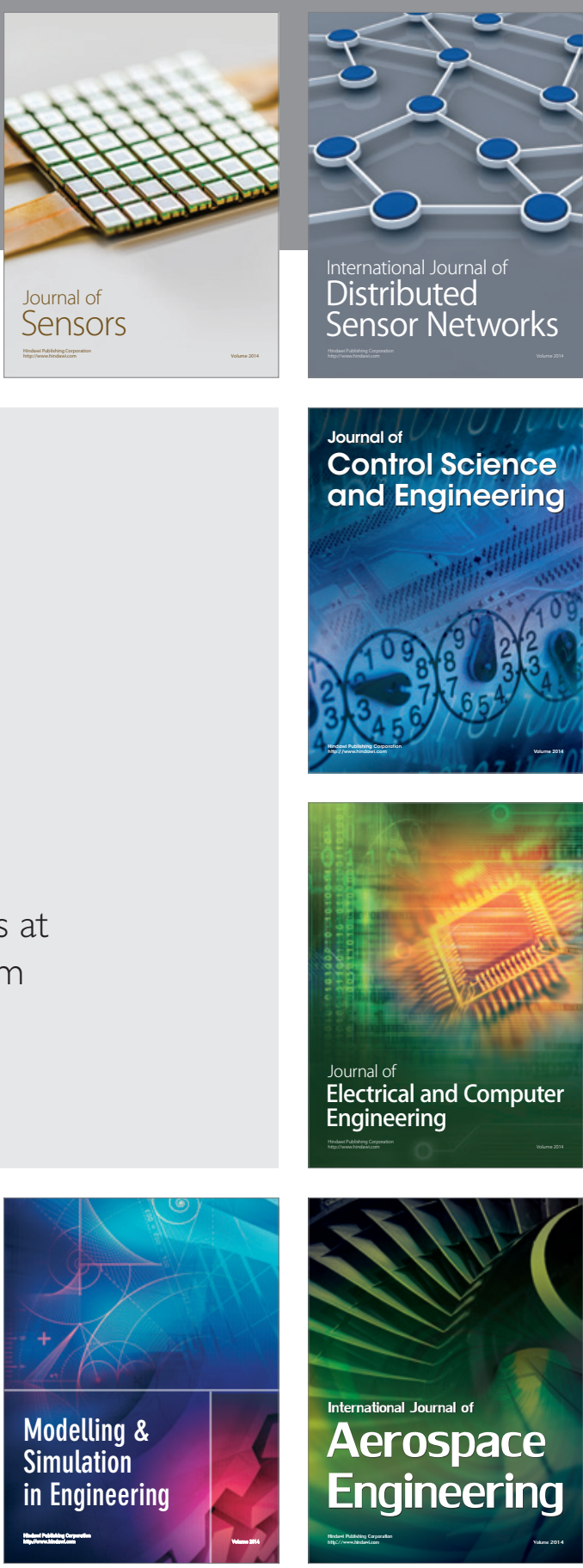

International Journal of

Distributed

Sensor Networks

Journal of

Control Science

and Engineering
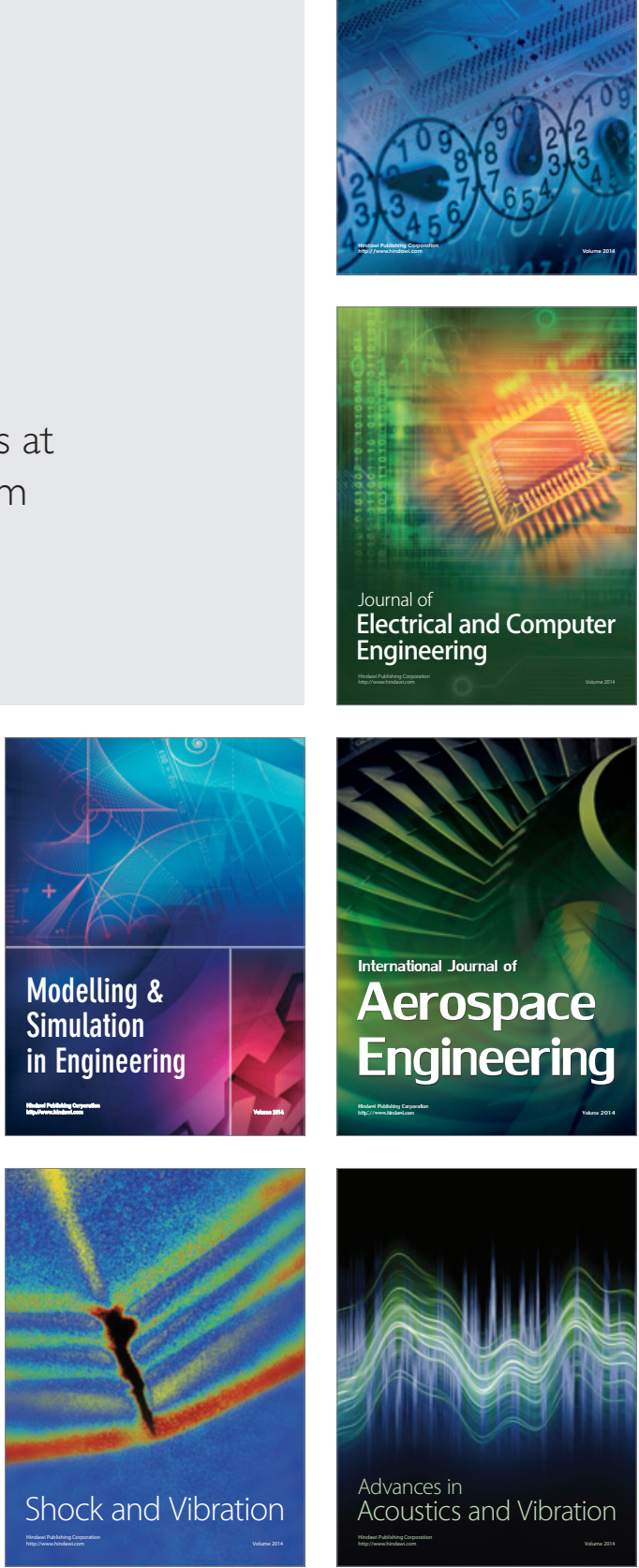